Thorax (1947), 2, 21.

\title{
THE TREATMENT OF PULMONARY HYDATID DISEASE*
}

\author{
BY \\ N. R. BARRETT
}

London

The treatment of pulmonary hydatid disease is a subject which has been seriously debated since 1804 when Laennec pointed out that hydatid cysts were but a phase in the life cycle of a tapeworm and not abnormal growths of human tissues. He had based this shrewd observation upon clinical and post-mortem studies, and to support his thesis he described a number of cases amongst which was that of a boy who died from the effects of giant cysts in the lungs.

In the recent past there has been a tendency to assume that the brilliant work of Frenchmen such as Dévé of Rouen (1922), of the Australasian Hydatid Registry under the late Sir Louis Barnett, and of South American surgeons had almost reached final conclusion, and few now challenge their experienced opinions. It is my purpose to debate some of the accepted views ; but my experience is limited, and my remarks should be judged accordingly. I shall refer to 30 patients who harboured 38 cysts in the lungs ; 6 were known to have cysts in other parts of the body as well as in the lung, and 4 were suffering from associated conditions (advanced pulmonary tuberculosis, silicosis, coronary disease, and status epilepticus) which importantly influenced the treatment of their hydatids. The patients were not all directly under my care, but I have had the opportunity of studying the course of the disease in 3 patients who were operated upon by Mr. C. Price Thomas, and in 1 treated by Mr. R. C. Brock. The remaining 27 patients have been under the care of Dr. Dillwyn Thomas and myself at Sully Hospital, Cardiff, and at Horton War Hospital, Epsom.

The following general statements are relevant to this subject.

1. The merits of opposed treatments should be assessed according to three separate criteria, namely, successful removal of the parasite, prevention of reinfestation, and whether the respiratory system of the patient remains unimpaired by the disease or its treatment.

2. It cannot be assumed that hydatid disease runs a clinical course which is the same in every country. The method and the risk of infestation is different in different places (in Australia the incidence is highest in sheep-rearing districts, whereas, in South Wales, Howells (1938) has shown that people living in the

*A paper presented on Nov. 9, 1946, at a meeting of the Society of Thoracic Surgeons of Great Britain and Ireland in Edinburgh. 
industrial areas are more prone to infestation than farmers). The lung is more often involved in patients living in Australia than in those who live in Europe ( 9 per cent of primary hydatids occur in the lung according to French authorities, and 25 per cent according to some Australians). The disease is a serious menace in countries such as Iceland, but is rarely seen in others, such as the United States of America. Finally, the treatment in vogue in any place is influenced by the surgical facilities available; where thoracic operations are hazardous, conservative measures will be preferred.

3. The parasite is a silent intruder in the lung; it develops so insidiously and without irritation that by the time signs or symptoms are manifest the disease is often far advanced. The presenting features and the radiological appearances often suggest commoner maladies, and time is wasted or ineffective treatment is assayed. When the diagnosis of hydatid disease has been made, it may still be uncertain whether there are one or more cysts, and whether they lie in the lung, the mediastinum, the pleural cavity, or the abdomen. Accurate preoperative diagnosis has a bearing on successful treatment.

4. There is a narrow margin between easy and uneventful cure on the one hand and adventurous failure on the other. The ma ragement of some cases is so simple that the possible catastrophes which mighi 'iave occurred escape the notice of those with little experience of the disease. Nor can consideration of the final results be taken as an infallible guide in favour of this or that treatment, for they may be misleading even though assessed in the ways described above. My own cases prove this point, for in final analysis the results are: 18 patients cured (for periods of 1 to 10 years), 5 patients successfully operated upon but still under treatment, 6 patients untreated, not traced, or not controlled, 1 patient dead. I regard these results as fairly good, but many of the patients have passed through dangerous crises on their way to health.

In this communication the same patients will be referred to on several occasions when different aspects of the treatment are under consideration, and the words " simple" and "cumplicated" used in reference to the hydatid cysts refer to the condition of the parasite itself and not to the changes which may have occurred in the lung around it.

\section{Conservative Treatment of Simple Univesicular Cysts}

Lendon (1902) divided the progress of an untreated hydatid cyst in the lung into seven distinct stages:

1. The latent phase, in which the parasite is growing but produces neither signs or symptoms, but in which it may be discerned in radiographs and in which biological tests may be positive.

2. Symptoms and signs, which are often due to anaphylaxis, appear. The cyst may die, or may continue to grow to an enormous size. In the past a dead cyst 
has generally been regarded as one in which further treatment is unnecessary ; but a dead cyst is a foreign body in the lung.

3. Rupture occurs, and this may cure the patient or cause chronic illness or death. If the tear in the laminated membrane is small the hydatid may leak, but it continues to live and this leads to the next phase.

4. A quiescent phase, in which the patient may appear to be cured but during which the parasite is still alive. This stage is often absent.

5. Expectoration of the mother cyst, which, if incomplete, leads to

6. Sepsis, daughter cyst formation, or both.

7. The empty sac left after expulsion of the germinal membrane.

Some of these stages may be marked in one case and absent in another, some may be prolonged, and others last but a moment of time ; but in any the question of treatment may arise.

In the beginning practically all patients were treated conservatively, but by the end of the last century methods had already been found of removing hydatid cysts from the lung. The successes of surgery have been so definite that little thought is now spent upon other methods (amongst 493 references given recently by Davidson (1944) scarcely any refer to this aspect), and the importance of removing the parasite is generally admitted. Nevertheless there are occasions in which, for one reason or another, an expectant policy may be adopted, and I shall begin by discussing this subject.

Table I records briefly the results of conservative treatment in the present series.

The conservative measures which have been used in the past are these:

1. Expectant treatment practised in the hope that spontaneous expectoration would occur, and favoured by those who feared the consequences of surgery. Such treatment carries the high probability that the disease will progress and that the patient may ultimately die from the disease or its complications.

2. Aspiration of the cyst. By the end of the last century many patients had been "cured" by aspiration of the hydatid fluid. But as early as 1895 Australian surgeons had proved the dangers of tapping; dangers which included sudden death, anaphylactic shock, leakage of hydatid fluid, flooding of the bronchial tree, haemorrhage, pulmonary suppuration, and daughter cyst formation. Tapping is absolutely contraindicated.

3. Artificial pneumothorax sometimes causes a cyst to rupture into the bronchus and to be completely expectorated. Much more often it fails, and lays the patient open to complications as well as to the possibility of rupture or herniation into the free pleural space. It should only be used preoperatively.

4. Drugs and radiotherapy are of no avail, and even if the parasite could be killed in this way a foreign body would remain in the lung. 


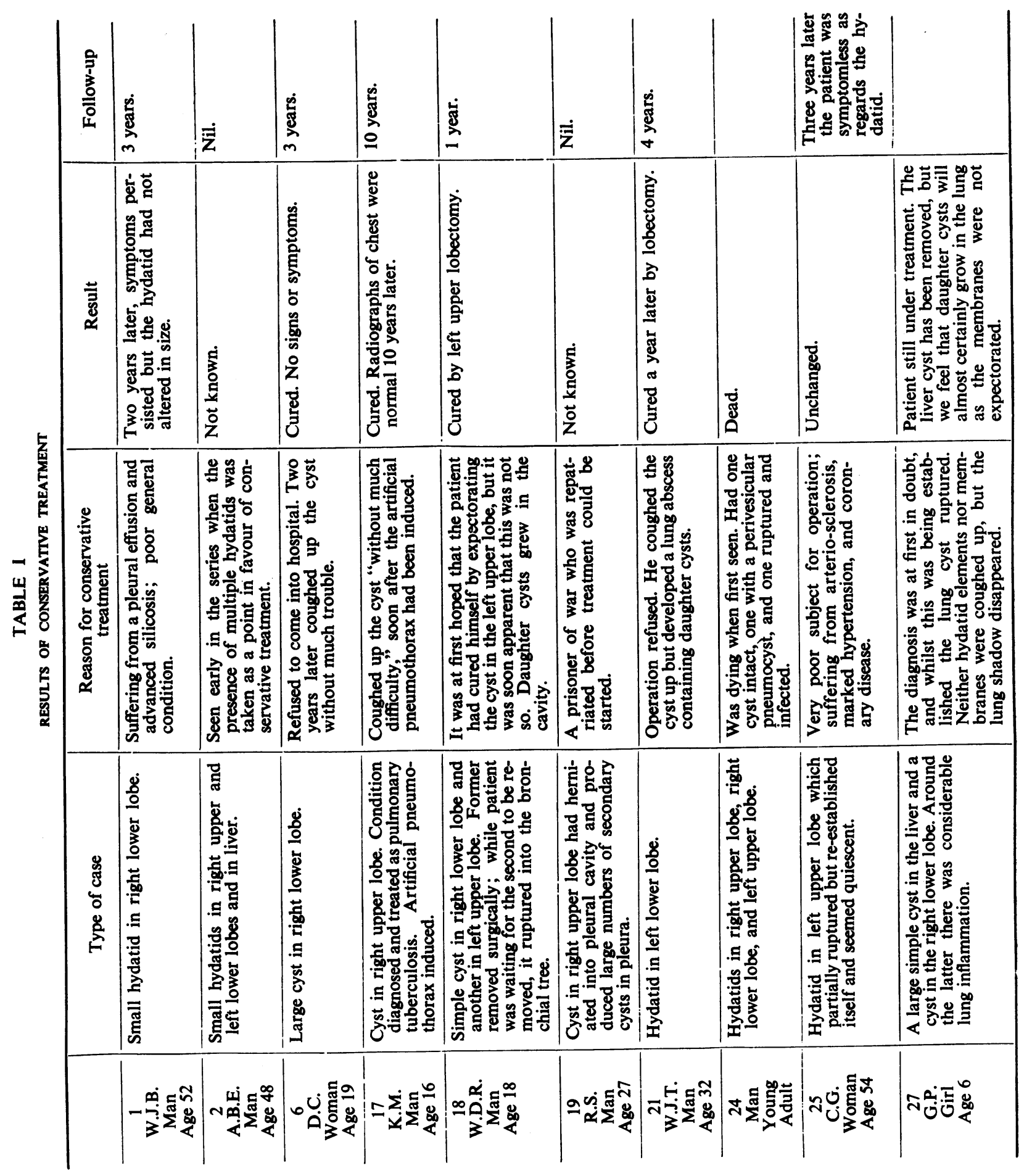

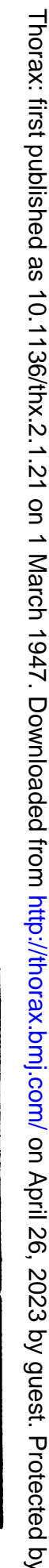




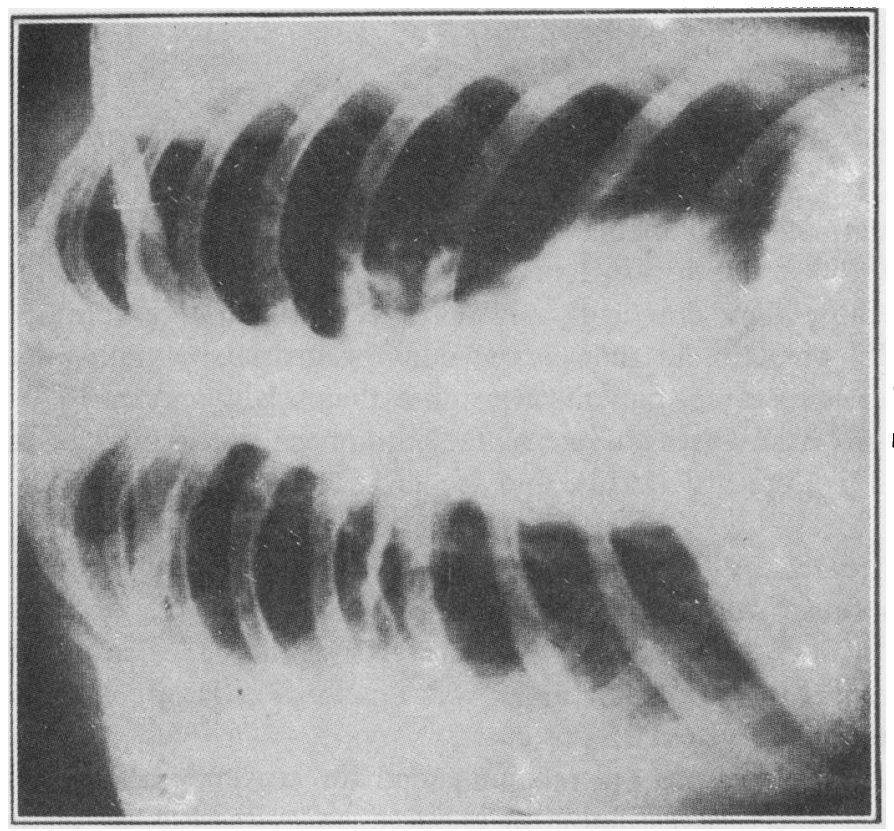

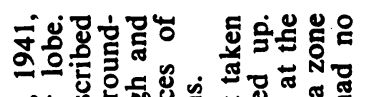

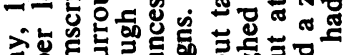

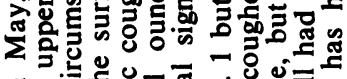

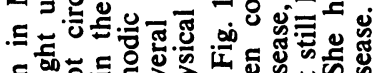

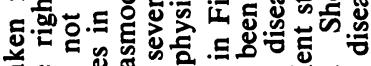

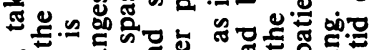

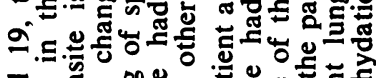

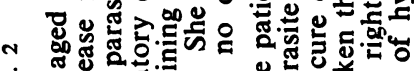

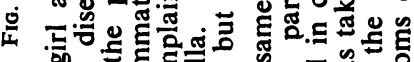
๙ 氜

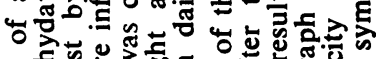

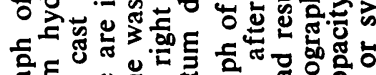

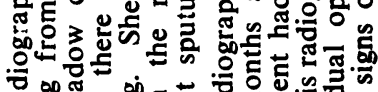
ซึ่

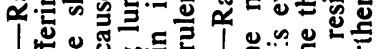

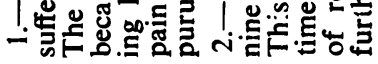
迹 这

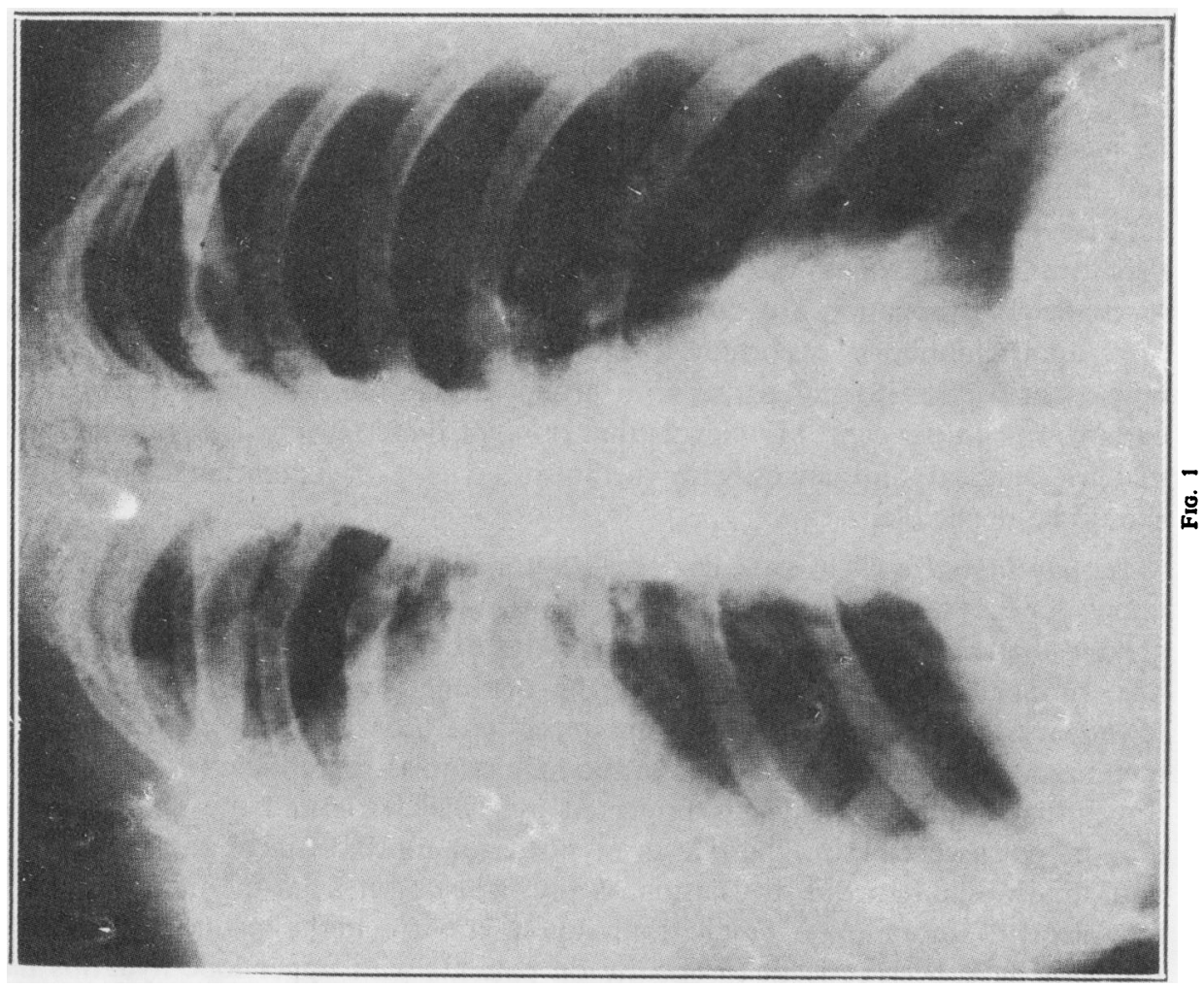


5. Bronchoscopy and attempts to rupture the cyst by percussion therapy are no longer used.

It is certain that complete spontaneous cure can occur by expectoration, and the figures which have been put forward in support of this underestimate the chances of success because they practically always deal with patients admitted to hospital. Dew (1928) pointed out that in the country districts of Australia, where medical facilities are scarce, patients who cure themselves may never be seen by a doctor and no record is available of their number; the failures come to hospital. Dévé (1922), Lepicard (1912), and Bellard (1924) concur with this opinion.

In 1889 Thomas (quoted by Samuel West, 1909), who was one of the most famous authorities in Australia, gave the following interesting statistics. In a group of 133 patients who coughed up their pulmonary hydatids, 31 died during the process and 80 recovered; the result in 32 was not known. It appears that the mortality from rupture was about 25 per cent.

Nowadays conservative measures are recommended for special types of case and some maintain that delay is justifiable in children, in cysts situated in the upper lobe, and in those called " hilar," "central," or " parabronchial." I oppose these views, but shall present the argument.

Children.-In children several points are said to favour a waiting policy. First, there is statistical evidence that spontaneous evacuation and complete cure frequently occurs ; if this be true, the reason may be that the chest wall is supple and transmits compression strains to the cyst which favour intrabronchial rupture, or it may be that the bronchi adjacent to the cyst are so delicate that they are easily eroded by the parasite, so that intrabronchial rupture and spontaneous evacuation are common events. Secondly, the mortality of operations upon children is, according to the published Australian figures, alarmingly high : Christie (1938) stated that in a group of children suffering from bilateral cysts it was 43 per cent. My view is that none of these reasons is valid, and with modern surgical and anaesthetic methods the risk of operations in children should be negligible.

Upper lobe cysts. - A case has also been made for conservative treatment for upper lobe cysts. It is said that the chance of spontaneous expectoration is greater than in lower lobe cysts because the downward drainage of the upper lobe bronchus favours evacuation of the disrupted hydatid elements. But the lower lobe bronchus is larger than the upper lobe bronchus and can transmit the membranes more easily ; the base of the lung is more susceptible to compression forces than the apex, which is protected by the clavicle and the scapula ; it is also more susceptible to the effects of powerful movements of the diaphragm, and, finally, spontaneous evacuation of any light object from the main bronchial tree depends more upon cough than upon gravity. Perhaps one reason why surgeons have been reticent to operate on patients with upper lobe hydatids has 
been that the ordinary two-stage operation is difficult to perform at the top of the thorax because the muscles, the clavicle, and the scapula are in the way. Using the technique I shall describe, there is no need to defer operation.

Cysts near the hilum.- The third group in which operation is often deferred is that in which the cyst is judged to lie near the hilum. This view dates back to the time when Finochietto (1927) put forward his theory that, for purposes of treatment, there were two varieties of parasite depending upon the position of the lesion in the lung. These he called "peripheral" and "central." They were differentiated because the former were in close apposition to the chest wall at a distance from large bronchi, and therefore were suitable for surgery and unlikely to be expectorated; the latter were treated conservatively for the opposite reasons. Central or parabronchial cysts were regarded as embedded in the hilum and surrounded on all sides by large vessels which coursed over their surface. Operative removal was thought to be dangerous because, being at a distance from the costal pleura, the adventitia could not be marsupialized, and because of the risks of serious haemorrhage and of air embolism; the patients were left until the parasite grew so large that it abutted upon the chest wall, or until it ruptured into a bronchus or a blood vessel.

Bird (1925) emphasized that small cysts occur near the root of the lung, that they are apt to have daughter cysts within them, that the adventitia becomes thicker here than in other parts of the lung, and that "they burst and a cure results naturally after a long period during which the physical signs are embarrassing to the physician." Many authorities have stated that rupture into a bronchus is likely to occur in 60 to 80 per cent of these cases.

True "parabronchial" cysts must, however, be rare, for the only way in which they could reach this site would be for the parasite to be carried in a bronchial artery. Such cysts, rare though they be, should be capable of removal, for surgical control of the main pulmonary vessels is now a routine procedure in many thoracic operations, and air embolism is a rare complication of such operations. "Central" hydatids present a slightly different problem. It is certain that the parasite which is carried to the lung in the blood vessels, in the same way as metastatic carcinoma, often lodges in the depths of a lobe and at a distance from the costal pleura. It is also known that when this Thappens the cyst tends to grow outwards, rather than in the direction of resistant structures like bronchi, and that the majority of lung hydatids ultimately become superficial in the region of the fourth rib in the midaxillary line. My own view is that long before "central" hydatids reach the costal surface of the lung many have presented upon one of the fissures or upon the mediastinum, and could be easily removed surgically if it were not necessary to marsupialize the cavity from which the parasite had been extracted. I have in fact operated upon several cases in which the cyst was presenting upon one of the fissures and in which, in radiographs, it seemed to lie in the very middle of a lobe. A final point is that the 
nearer an embryo lodges to the hilum the nearer it lies to a mediastinal or fissural pleural surface, and, in consequence, the sooner it becomes operable. For these reasons I submit that uncomplicated central cysts can be safely treated by surgery and that delay on this account is no longer justifiable.

Size of the lesion.-Apart from the above considerations there are others which may dictate an expectant policy. The size of the lesion has a bearing upon treatment. There are recorded cases of giant cysts which apparently caused no symptoms. Some of these were discovered in patients dead from other causes : they should be regarded as interesting curiosities and not as an argument against surgical removal of the parasite. At the other extreme are small hydatids, and since the introduction of mass radiography a number of these cases have been correctly diagnosed. Parasites which are no larger than a pea cast a definite shadow in the lung field, and this shadow cannot at first be distinguished from other lesions, such as tuberculosis. But if it be a hydatid it grows steadily in size, maintaining its form-which is approximately spherical-and it incites no inflammatory reaction in the surrounding tissues. The diagnosis in these cases can only be made by excluding other clinical conditions which are more common and by studying serial radiographs; absolute reliance cannot be placed upon a positive Casoni reaction. In my experience there have been six occasions on which an immediate positive Casoni reaction was found in patients who were, in fact, suffering from other conditions ; in all of these the fluid which was used for the test had been tested upon a patient suffering from hydatid disease and was active. The cases were a woman from whom Mr. Price Thomas removed a granuloma of the diaphragm, a man who died with generalized abdominal carcinomatosis, a man who died from carcinoma of the bronchus, and three other patients with secondary carcinoma in the lung.

A small cyst is harmless. I believe that it should be watched until such time as it is considered to have reached the pleural surface in any part of the lung, and then removed.

\section{The Case for Surgical Removal}

It follows from the preceding remarks that surgical removal of lung hydatids is the ideal and that conservative treatment is a policy of despair. The case in favour of surgery depends upon the following observations.

Lung cysts, both large and small, can be totally expectorated by coughing, and complete restoration of the lung to normal can occur; but no man can predict which patient will evacuate the parasite spontaneously and which will develop anaphylaxis, daughter cysts, suppuration, or other complications. It is admitted that statistical evidence suggests that under certain conditions a spontaneous cure is more probable than in others. It is also true that simple cysts may remain apparently dormant for long periods of time and there is no proof that they all progress inevitably. The risk of bronchial dissemination after 
expectoration is negligible. On the other hand many of the so-called spontaneous cures cannot be accepted as complete, and, if a waiting policy be adopted, serious complications may occur at any time ; these increase the risks of surgical treatment importantly. The complications are leakage or rupture of the hydatid either into the bronchial tree, into a blood vessel, or into the pleural cavity. The ruptured cyst may flood the bronchial tree, or its membrane may impact in the larynx and kill by suffocation or anaphylactic shock. It may, after partial rupture, remain uninfected and bud off daughter cysts, a development which is always attempted by the parasite when its life is threatened, or it may become infected and produce a chronic lung abscess containing sphacelated hydatid remnants surrounded by spreading pulmonary suppuration. In addition the growth of a space-occupying lesion in the lung leads eventually to bronchial occlusion, to haemoptysis due to congestion around the cyst, to tension pneumothorax, pleural effusion, and empyema. Bird (1925) pointed out that rupture of lung cysts precedes suppuration (the opposite sequence to that observed in liver cysts). He stated that if an infected cyst ruptures into the pleural cavity the accident is generally fatal because the space is contaminated with a massive dose of decomposing hydatid remnants. "Several such cataclysms have been seen and smelt by me and in spite of very free opening and oxygen lavage the patients have sweated through sepsis to a miserable death."

These are the arguments, and surgeons must prove that the risks of surgical treatment are not only smaller than the risks of waiting, but that the operation cures the patient and does not affect the respiratory system adversely. There are cases where delay should be advised; these are patients whose cysts are small and silent and who can be kept under observation until the opportune moment for surgery comes; patients suffering from conditions which are more immediately dangerous to life such as advancing pulmonary tuberculosis; and those who refuse operation.

\section{Surgical Removal of Simple Univesicular Cysts}

The surgical treatment of a simple hydatid is importantly influenced by the presence or absence of pleural adhesions. Fossati (1911) and Lamas (1916) of Uruguay, both postulated that adhesions should be regarded as evidence of inflammation in the lung around the cyst. If a wide area of pleural symphysis is present it is reasonable to assume that, although the hydatid itself may be intact, inflammation has occurred in the lung and involved the pleura. But pain, which is an early symptom of pulmonary hydatid disease, is not due to pleurisy and is not likely to be followed by pleural adhesions. The cause of this early pain is not known, but I believe that it is due to the tension in and around the parasite ; it is not characteristic of pleurisy. One of our patients complained of pain over a period of 19 years, and at operation there were no pleural adhesions but a simple cyst was found embedded in the chest wall; it had eroded two ribs 


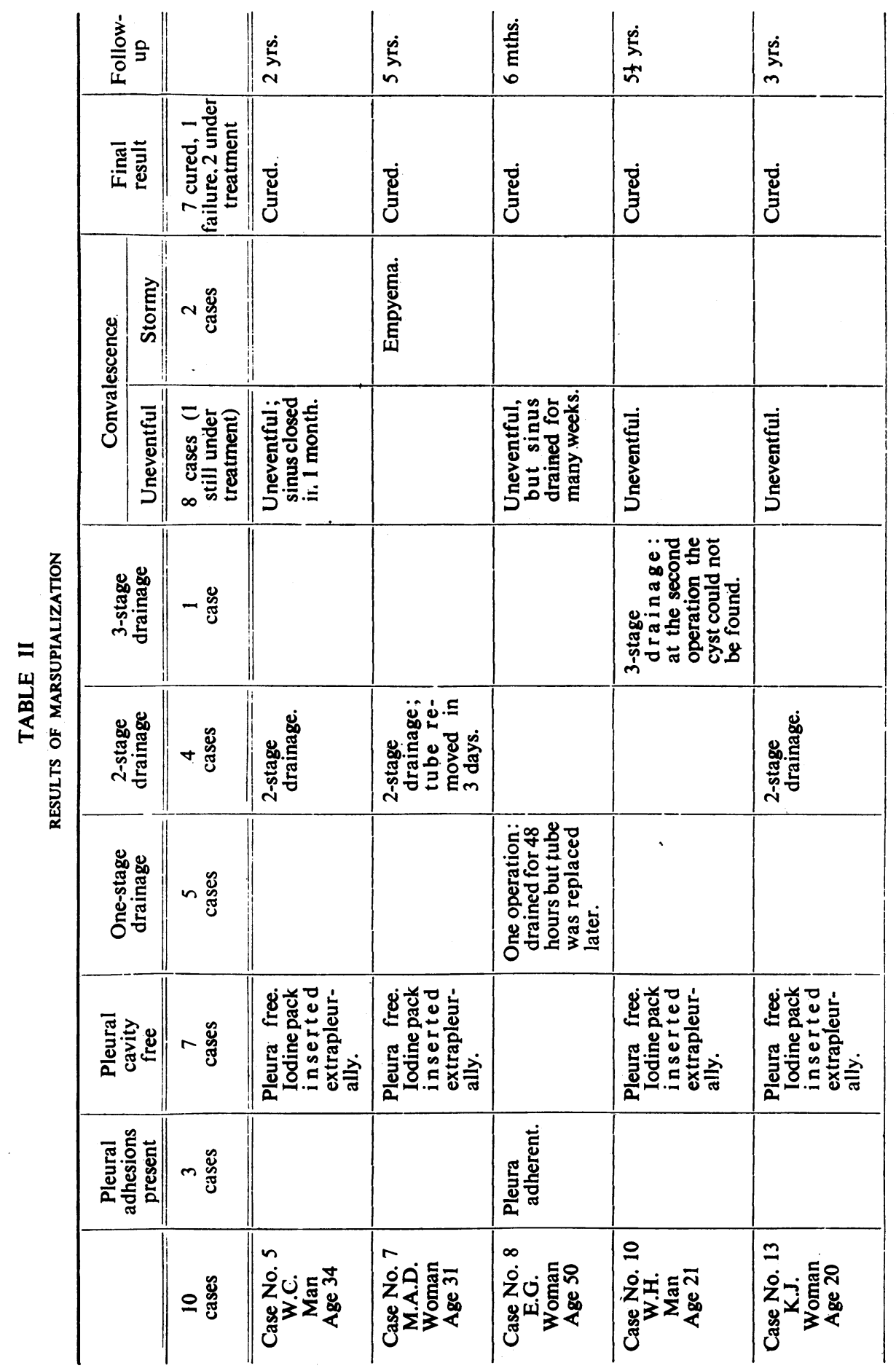

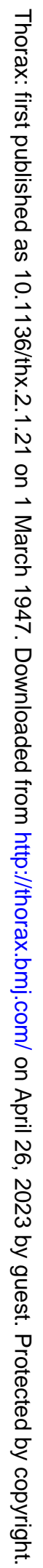




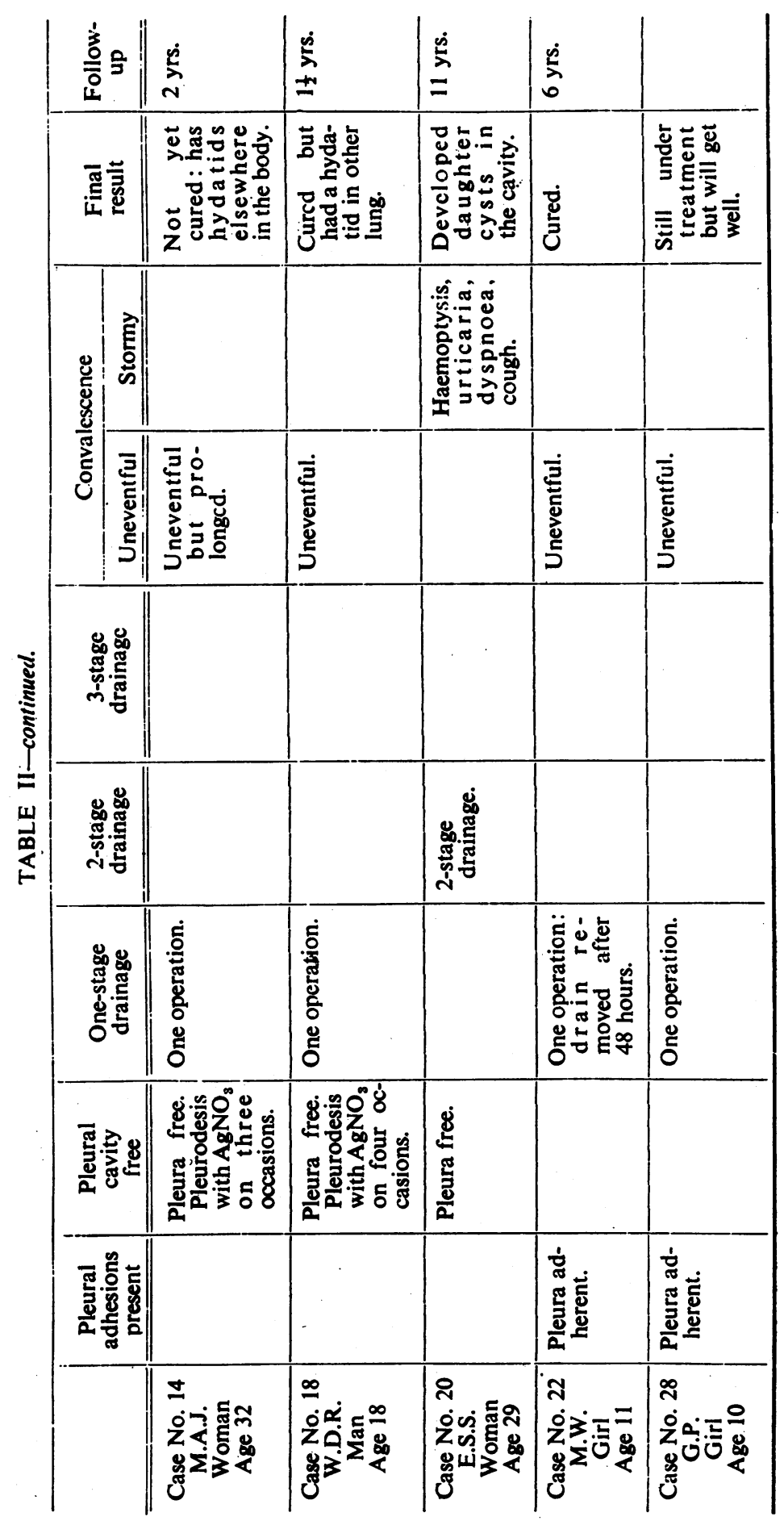

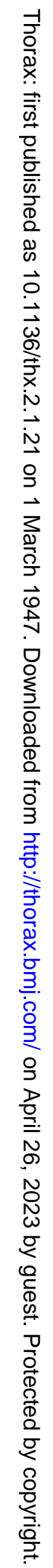


and the pain was presumably due to displacement of and pressure upon the intercostal nerves.

Simple pulmonary hydatids are rarely complicated by adhesions, and if removal, marsupialization, and drainage are contemplated pleural symphysis must be artificially created. In our experience the latter is not easy and adhesions are often insecure or incomplete ; we have used the usual two-stage operation, placing an irritant extrapleural pack adjacent to parietal pleura at the first opera. tion, and have tried intrapleural.injections of silver nitrate as advised by Brock (1942). On one occasion the iodine pack sloughed into the pleural cavity and on several others serous effusions occurred. Some cases were, however, entirely satisfactory.

Christie (1938) wrote, "The accepted treatment is by resecting a portion of rib or ribs over the cyst as localized by $x$-ray examination, by evacuation of the mother membranes after complete tapping, and then by fixation of the cyst wall (the adventitia) to the parietes with a drainage tube in situ for five to ten days, or until such time as the discharge disappears. That is to say . . . open drainage." Lindemann (reported by Barnett, 1914) was the first to recommend marsupialization. This method with minor modifications has been used on ten occasions in this series. The operations were all performed under local anaesthesia and the results are given in Table II. These cases show that removing the parasite across a zone where the pleural space has been obliterated gives good results, but in our hands the method is not without disadvantages and difficulties. These are as follows :

(a) Success depends upon accurate preoperative localization: this should be possible but is not always achieved. Indeed I have become impressed by the fact that it is impossible to embark upon an operation for pulmonary hydatid disease knowing certainly what will be found or what actual surgical treatment will be necessary.

(b) Pleural adhesions are generally absent. They must be created, either by injecting irritants, such as silver nitrate, into the pleural cavity, or by using an extrapleural pack.

(c) In order to localize the cyst when the pleura has been exposed it is often necessary to aspirate the suspected area. But aspiration for the purpose of localization is not desirable because hydatid fluid inevitably leaks along the needle track.

(d) However secure pleural adhesions may appear to be, pleural complications can occur. It has been authoritatively stated that 25 per cent of cases develop a septic pleural effusion. This has not been our experience.

(e) If the adventitia be sewn to the chest wall after the cyst has been removed it may tear away later and the patient may develop pleural effusion, pyothorax, or tension pneumothorax. These complications are likely if the patient gets an anaphylactic reaction and coughs or becomes dyspnoeic.

(f) A drain left in the cavity which has been marsupialized encourages secondary infection to enter, and although this is generally insignificant it may be important; it may cause a persistent sinus.

Believing that these disadvantages should be overcome, we tried other methods and at first met serious obstacles. 
In December, 1940, I operated upon a man aged 21 (Case No. 10) who had bilateral univesicular simple cysts. Under general anaesthesia the right pleural cavity was opened and was free. The cyst could easily be felt in the right lower lobe and was presenting in the fissure between the lower and middle lobes. The area was packed off and the cyst easily removed after slow aspiration. No bronchial fistula was seen. The incision in the adventitia was closed with two layers of sutures around a small drain which was brought out upon the surface. The lung in the vicinity of the drain was sewn to the chest wall and the air in the pleural cavity was aspirated. The patient stood the operation very well. On the following day he developed a violent spasmodic cough, and during one of these attacks the lung tore away from the chest wall. This caused a tension pneumothorax, massive surgical emphysema, and atelectasis. To meet these serious complications a needle, connected to a suction apparatus, was inserted into the pleural cavity anteriorly in the second interspace. The condition of the patient was now critical. Four days later the thoracic emergency had been controlled but acute dilatation of the stomach had developed. Fortunately he did not develop an empyema, and ultimately he made a complete recovery and has been classed among those who are cured.

This case impressed us that thoracotomy was an excellent way of actually dealing with the parasite, but that it was dangerous either to sew the lung to the chest wall or to close the pleural cavity without suction drainage after the operation.

For many years surgeons experienced in this type of work have advocated thoracotomy for cases in which there were no pleural adhesions. Bird (1925), Finochietto (1924), Dew (1928), and South American surgeons were the pioneers. The operations they describe are all basically the same, but differ in points of detail. Ceballos (1943) recorded a series of 20 patients who between them underwent 24 thoracotomies: 19 were cured, and 1 died from pulmonary abscess and bronchopneumonia. He recommended a thoracotomy under general anaesthesia. The cyst was localized in the lung; the latter was then inflated by positive intratracheal pressure so that it bulged into the incision in the chest wall, where it was fixed by sutures passed through the lung and the adventitia. The parasite was removed after aspiration of its contents and the residual cavity in the lung was drained. In my hands this type of operation is not safe. Not only is there a danger that the sutures which anchor the lung to the chest wall will not shut off the pleural cavity completely and that they may tear away, but it is only applicable to hydatids which can be approximated to the chest wall.

Having established a diagnosis of simple pulmonary hydatid disease I now proceed as follows. A bronchogram of the affected side is made in order to ascertain whether the bronchi distorted by the cyst are bronchiectatic; in fact the lung adapts itself so readily to these tumours that irreversible bronchiectasis is unusual. On the day before operation a shallow artificial pneumothorax is induced to find out whether diffuse pleural adhesions are present ; local adhesions can only be certainly discovered at thoracotomy, and for purposes of treatment such cases should be regarded as having a free pleural space. The artificial pneumothorax is induced shortly before the operation to minimize the chance of rupturing the parasite or of allowing it to herniate out of the lung into the pleural 
cavity. If the pleural cavity is free I do a thoracotomy under cyclopropane anaesthesia and controlled respiration. The relative merits of local as opposed to general anaesthesia, and of positive pressure anaesthesia as opposed to controlled respiration, are well known and will not be discussed. But if general anaesthesia be used induction must be smooth, without cough, straining, or respiratory obstruction, and at the moment the parasite is evacuated from the lung the plane of anaesthesia should be light in case hydatid fluid or blood escapes into the bronchial tree. Control of the situation in an emergency demands intratracheal intubation.

A limited intercostal incision generally suffices unless a lobectomy has been planned. The cyst is located and the area packed off with pads (Dew recommends black pads for this purpose, because if scolices be spilt when the cyst has been opened they can easily be seen as white dots) so that only a small zone of lung or of adventitia is exposed, and a fine, long needle is passed into the cyst. (Many surgeons have devised special apparatus for aspirating the cyst.) This needle is connected to a two-way tap and $20 \mathrm{ml}$. syringe; the former carries a piece of rubber tubing which passes into a bottle. The hydatid fluid is aspirated slowly. The object of slow aspiration is to prevent the cyst tearing as the laminated membrane separates from the adventitia, and aspiration should be continued only as long as the fluid comes off quite readily. The aim is to convert the tense hydatid into a lax cyst which can be extracted through a small hole. It is unnecessary and inadvisable to draw off too much fluid. If an attempt be made to get the cyst dry, the needle inevitably slips out of the membranes which have become shrunken and curled up, and contamination of the adventitia occurs ; daughter cysts may then form at a later date. As soon as the aspirating needle has been passed into the cyst, a sucker is applied to the surface of the lung close to the needle because the fluid in the cyst is under considerable pressure and is apt to leak around the needle.

After partial aspiration some surgeons have advised that a 1 per cent solution of formalin be injected into the hydatid through the needle; this is contraindicated because the membranes may rupture and allow the formalin to leak into the bronchial tree. When the cyst has been partially aspirated, and with the needle in place, an incision about half an inch long is made down to the laminated membrane. The difference in texture and colour between the lung, the adventitia, and the laminated membrane is so obvious that there is no difficulty in locating the latter. The presenting part of the laminated membrane, which is still intact, is then grasped with non-toothed tissue forceps and slowly drawn up into the incision so that a firmer hold can be obtained with plain ring forceps. By gently elevating the lax cyst it can generally be removed intact through the small incision in the adventitia. In this way large cysts can be removed through a small incision in the adventitia. I have found it difficult to remove daughter cysts intact, as these tend to rupture easily. It is wrong to incise the laminated 
membrane and to plunge a sucker into the cavity, because by this procedure hydatid fluid is inevitably spilt and the laminated membrane tears and turns inside out. This is due to the peculiar structure of the membrane; its outermost fibres are under more tension than those adjacent to the germinal layer, and, like cellophane, it tears easily as soon as a split has been started. If the cyst turns inside out before it can be extracted from the lung, not only is the patient exposed to the risk of anaphylaxis, but the tissues are contaminated by hydatid sand (brood capsules).

If, when the thorax has been opened, the cyst is found to lie in the middle of a lobe at some distance from the pleural surface, the pericyst can be exposed by cutting through the lung at the point where the parasite most nearly approaches the surface. It is possible to do this without much bleeding by approaching the zone between two bronchopulmonary segments, as in segmental lobectomy.

When the parasite has been lifted out of the lung the remaining cavity is inspected with a light. It is generally dry, and has no fistulae opening upon it, but if there are small spurting vessels in the pericyst these must be controlled. If the cyst has been large, or if there has been inflammation around it, some muco-pus may be found in the space between the pericyst and the laminated membrane. The presence of exudate in this space indicates a pre-existing defect in the pericyst, and possibly in the parasitic membranes as well, and, in viscera other than the lung, is an absolute indication for drainage. Barnett (1938) stated, however, that infection in this type of case is generally of low virulence, and the complication is not likely to be met if the case has been properly assessed before operation. For this reason I believe that if penicillin and sulphonamide powder be left in situ the exudate can safely be ignored unless gross inflammation be present. The next step is to close the incision in the adventitia without drainage, and to cover the suture line with visceral pleura by invaginating the lung surface locally. The chest wall is then closed and an apical catheter inserted for suction drainage of the pleural cavity.

In a personal communication Ronald Edwards describes a technique for obliterating the residual cavity left in the lung after removal of the parasite. "I open the cavity widely so that I get a good view of the bottom. A number of fairly deeply placed sutures are then inserted in the pericyst starting at the base and working up to the periphery. Finally a running suture is inserted along the surface of the lung. A little penicillin and sulphathiazole powder is sprinkled in the cavity before suturing. This technique seems to give good results in the case of simple cysts which are clearly demarcated in the radiographs, but I have not tried it in chronically infected cysts in which the pericyst is dense-in this type of case lobectomy is the method of choice."

Closure of the pericyst without drainage in uninfected cases was established as a sound procedure for abdominal hydatids by Bond (1891), and a somewhat similar step had already been recorded by Thornton (1883) and Billroth in 1890 . 
The point has been confirmed by Moore, Syme, Hamilton-Russell, and Barnett in Australasia, but in the case of pulmonary hydatids this step has not been generally acceptable and the usual practice is to sew the lung to the chest wall and drain the cavity. Unless this is done there are two probable complications, namely, infection and tension pneumothorax. The former is not important because it rarely occurs, but the latter is dangerous. I submit that the "empty sac" should not be drained and the lung should not be sewn to the chest wall, but if tension pneumothorax and all its complications is to be avoided a catheter must be left in the pleural space and connected to a suction apparatus. My own preference is for an apical catheter introduced through the second intercostal space between the midline posteriorly and the vertebral border of the scapula. The tube enters the pleura at the top of the chest and should extend about two inches downwards. Through this tube air is sucked out of the pleural cavity, thus causing the lung to expand, and if fluid collects it can readily be taken off. Experience in the treatment of haemothorax has convinced us that a suction catheter at the top of the pleural cavity achieves complete expansion of the whole lung more surely than one placed at the bottom. In this, as in most intrathoracic operations, the immediate postoperative aim is to get and to keep the lung completely expanded at the earliest moment.

I have used the technique described above on eight occasions, and the operative and postoperative course of the patients has been easy and satisfactory; it represents the ideal so far as my own investigations go. The advantages of this operation are that hydatids in any part of the lung can be removed. The extreme apex, the hilum, the interlobar fissures, and the mediastinal aspects are all accessible, and, as no attempt is made to anchor the cyst to the chest wall, there is no need to delay operation until the cyst is so large and peripheral that this could be done. Moreover, multiple cysts in one lung can be eradicated at a single operation, and the parasite can be approached directly at its most superficial point rather than from the subcostal surface of the lobe. Finally, if the diagnosis be at fault, surgical treatment can be modified to suit the circumstances.

After removal of simple pulmonary hydatids the "empty sac" generally obliterates quickly, and even if the space has been drained postoperatively a cure generally occurs. Christie (1938) stated that in 7 cases $16,18,19,21,23,25$, and 35 days elapsed before the residual cavity in the lung had healed completely : but he adds that in 1 infected case the period was $2 \frac{1}{2}$ months, in 2 others 3 months, and in others 4 months, 10 months, and 4 years. When the cavity persists beyond a period of six months it becomes likely that it will never disappear and lobectomy may be necessary to cure the patient. This is especially true if one or more bronchial fistulae communicate with the space. A persistent "empty sac" may complicate any type of operation except lobectomy.

It is not unusual for cysts situated near to the surface to herniate out of the lung and to drop to the base of the pleural cavity. This can happen without 

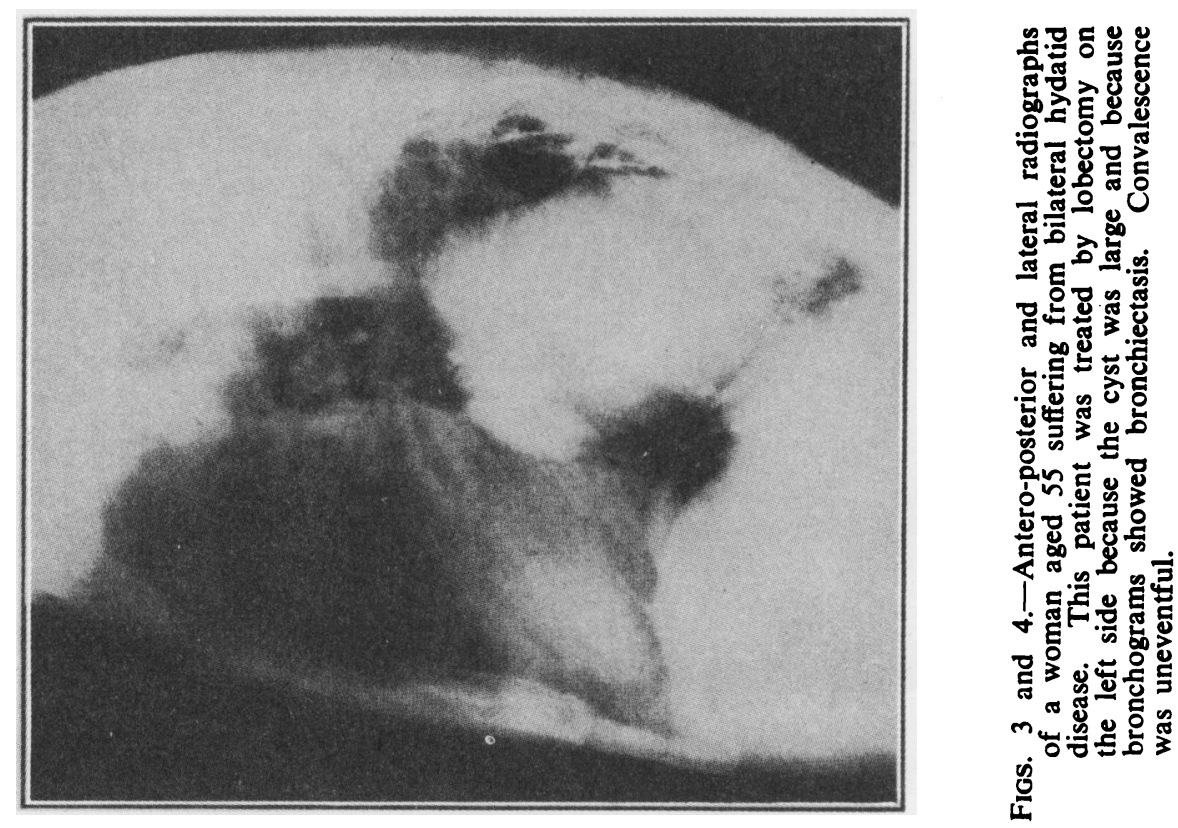

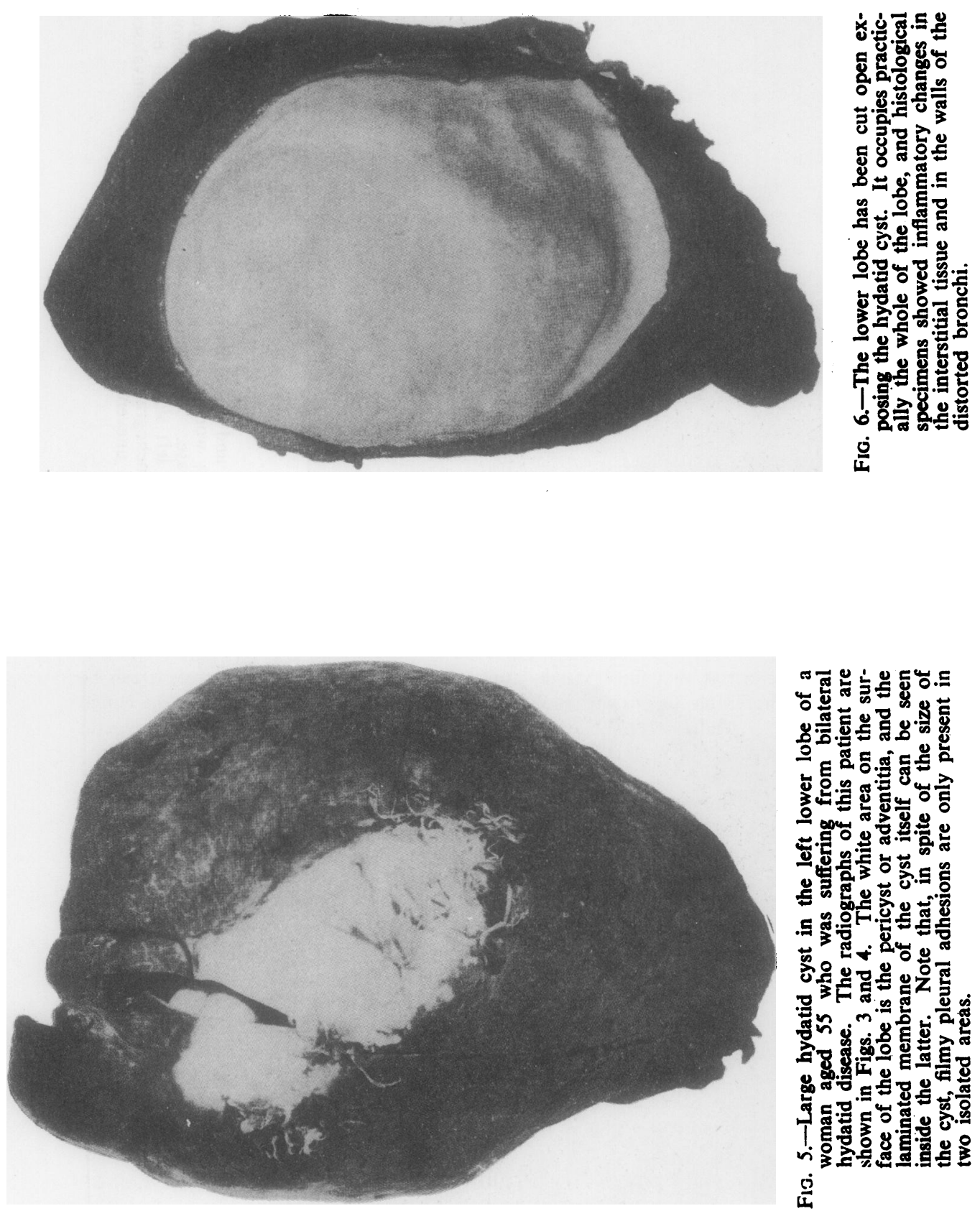
symptoms or it may be discovered on account of haemoptysis, spontaneous pneumothorax, tension pneumothorax, or anaphylactic signs. If the cyst remains intact in the pleural cavity it develops a new adventitia and continues to grow ; if it ruptures during extrusion from the lung the pleural cavity may be seeded with innumerable small secondary parasites, and these rapidly grow into adult cysts. This occurred in one of our patients, but he was a prisoner of war and was repatriated before treatment could be instituted. He was at first considered to be suffering from pulmonary tuberculosis and the pleural seedlings were mistaken for fibrin bodies ; the correct diagnosis was made by Price Thomas at thoracoscopy. Simple cysts and uninfected secondary echinococcosis involving the pleural cavity should be treated by thoracotomy and removal of the parasites.

There are certain circumstances in which $I$ believe a primary lobectomy is indicated in preference to the operation described above for simple hydatids, namely for simple cysts which are practically as large as the lobe they occupy, for simple cysts which are old and have a tough adventitia, and for simple cysts which have caused bronchiectasis or pulmonary suppuration. If the cyst is small and lies at some distance from a pleural surface I would do a segmental lobectomy.

The remarks I have made must be qualified, for there is as yet no royal road to success in every case, and there are objections to thoracotomy done under general anaesthesia.

(a) As there is a risk that the cyst may rupture and flood the bronchial tree, it can be argued that it is preferable to operate under a local or spinal anaesthetic so that the cough reflex is intact. As against this, anaphylactic shock is said not to occur under general anaesthesia (although Dévé has stated that delayed symptoms may occur whatever the anaesthetic), and rupture is unlikely if the cyst is treated with respect.

(b) However carefully the cyst may have been aspirated, and however fine the needle used, the laminated membrane may tear and fluid may find its way into the bronchial tree. If this happens, immediate evacuation with a strong suction apparatus of the fluid still left in the cyst may be necessary to save the life of the patient, but in the presence of a free pleura this disseminates hydatid elements far and wide; any operation which involves thoracotomy across a free pleural space must be designed to avoid secondary echinococcosis in the pleura.

(c) Bird (1925) stresses the possibility of unavoidable and even fatal haemorrhage when simple cysts are removed. The blood vessels in the pericyst may in places lie so close to the laminated membrane that they rupture when the cyst which supports their attenuated walls is suddenly removed. This haemorrhage is said to be more difficult to control when the chest is open than when a two-stage operation has been done. I believe the opposite to be true, for the hilum of the affected lobe can be grasped with the fingers or a tourniquet applied, and a lobectomy can be done. In any event massive bleeding is unusual.

Treatment of Multiple Simple Hydatids in One Lung and in Both Lungs

The presence of multiple cysts in the lungs is generally the result of primary infestation, but Sir Louis Barnett has stressed that they can arise in two other ways. Bronchogenic spread, which is not difficult to produce in animals, has been 
reported in man, and rupture of a cyst elsewhere in the body into a blood vessel can cause diffuse dissemination. Peacock and Hicks (1863) reported the necropsy of a man who died with a partially collapsed cyst in the right ventricle of the heart; they also found numerous pulmonary hydatids, as well as others in the liver, the spleen, and the kidneys. A number of similar cases have been described by Samuel West (1909) and Phillips (1930).

Of the 30 patients here recorded, 3 had more than one cyst in one lung and 6 had bilateral disease. This incidence of bilateral disease is high. Christie (1938), reviewing the Australasian literature on this subject, stated that in 1937 there were 1,350 cases of hydatid disease in the Australasian Hydatid Registry, and of these 250 were classified as lung cysts. Amongst this group only 15 had bilateral disease, and he added one further case. The points of special interest in Christie's paper are: (a) that the mortality rate in the 16 cases was 25 per cent, but if two early cases were excluded (they were treated with radiotherapy) it was 12.5 per cent; (b) that 7 of the patients were children under 8 years of age, and 3 of these died after operation ; and (c) that 4 patients had more than one cyst in one or both lungs.

Table III gives a brief epitome of the bilateral cases in my series. I submit that patients with bilateral simple univesicular cysts should be treated by bilateral thoracotomy under general anaesthesia in the way already described. If the details and precautions mentioned are observed the results should be good. There is an added risk in these bilateral cases, namely, that the patient may be sensitized by the first operation and develop anaphylaxis at, or after, the second. Fortunately this complication is unusual; but it is a possibility in any scheme of treatment which involves multiple operation, operations after rupture, or diagnostic aspiration. The actual amount of hydatid fluid which may have been spilt into the tissues, be it large or small, has no bearing upon whether the patient is sensitized or not.

If one or more of the hydatids is "complicated" the treatment must be modified accordingly, and lobectomy, pneumonectomy, or drainage may be indicated.

\section{Treatment of "Complicated Lung Cysts"}

Dew stated in 1928 that not more than 25 per cent of patients suffering from pulmonary hydatid disease were diagnosed before the onset of complications. This is no longer true, for improvements in radiography, and particularly in mass radiography, expose a higher percentage of silent lesions. In the present series 16 patients had simple hydatids when first seen and 14 had complicated cysts. Amongst the latter were some with daughter cysts in the lung and some with secondary echinococcosis.

If a patient coughs up daughter cysts the parent, or primary, hydatid is often in the liver, because daughter cysts are unusual in the lung and common in the 
TABLE III

bilateral CASES IN THE PRESENT SERIES

\begin{tabular}{|c|c|c|c|c|c|}
\hline & $\begin{array}{l}\text { Position of } \\
\text { cysts in the } \\
\text { lungs }\end{array}$ & Type of cyst & Treatment & Result & $\begin{array}{l}\text { Follow-up since } \\
\text { last operation }\end{array}$ \\
\hline $\begin{array}{c}\text { Case No. 2 } \\
\text { A.B.E. } \\
\text { Man } \\
\text { Age 48 }\end{array}$ & $\begin{array}{l}\text { Right upper lobe. } \\
\text { Left upper lobe. }\end{array}$ & $\begin{array}{l}\text { Simple. } \\
\text { Simple. }\end{array}$ & Conservative. & $?$ & $\begin{array}{l}\text { Ten years later, } \\
\text { letters returned } \\
\text { dead letter } \\
\text { office. }\end{array}$ \\
\hline $\begin{array}{c}\text { Case No. } 3 \\
\text { R.B. } \\
\text { Giri } \\
\text { Ag̨e } 9\end{array}$ & $\begin{array}{l}\text { Right lower lobe. } \\
\text { Left lower lobe. }\end{array}$ & $\begin{array}{l}\text { Simple. } \\
\text { Simple. }\end{array}$ & $\begin{array}{l}\text { Thoracotomy. } \\
\text { Thoracotomy. }\end{array}$ & $\begin{array}{l}\text { Cured. } \\
\text { Cured. }\end{array}$ & 1 year. \\
\hline $\begin{array}{c}\text { Case No.10 } \\
\text { W.H. } \\
\text { Man } \\
\text { Age } 21 \\
\end{array}$ & $\begin{array}{l}\text { Right lower lobe. } \\
\text { Left lower lobe. }\end{array}$ & $\begin{array}{l}\text { Simple. } \\
\text { Simple. }\end{array}$ & $\begin{array}{l}\text { Thoracotomy. } \\
\text { Three-stage } \\
\text { drainage. }\end{array}$ & $\begin{array}{l}\text { Cured but } \\
\text { convalescence } \\
\text { stormy after } \\
\text { thoracotomy. }\end{array}$ & 5 years. \\
\hline $\begin{array}{c}\text { Case No.18 } \\
\text { W.D.R. } \\
\text { Man } \\
\text { Age 18 }\end{array}$ & $\begin{array}{l}\text { Left upper lobe. } \\
\text { Right upper lobe. }\end{array}$ & \begin{tabular}{|l|} 
Simple. \\
Partial rup- \\
ture devel- \\
oped \\
daughter \\
cysts.
\end{tabular} & $\begin{array}{l}\text { Two-stage } \\
\text { drainage. } \\
\text { Lobectomy. }\end{array}$ & $\begin{array}{l}\text { Cured. } \\
\text { Cured. }\end{array}$ & 6 months. \\
\hline $\begin{array}{c}\text { Case No.24 } \\
\text { Young } \\
\text { Man } \\
\text { Age 19 }\end{array}$ & $\begin{array}{l}\text { Right upper lobe. } \\
\text { Right lower lobe. } \\
\text { Left upper lobe. }\end{array}$ & $\begin{array}{l}\text { Perivesicular } \\
\text { pneumocyst. } \\
\text { Simple. } \\
\text { Ruptured } \\
\text { and infec- } \\
\text { ted. }\end{array}$ & $\begin{array}{l}\text { Conservative. } \\
\text { Patient mori- } \\
\text { bund on } \\
\text { admission. }\end{array}$ & Dead. & \\
\hline $\begin{array}{c}\text { Case No.30 } \\
\text { Mrs. D. } \\
\text { Age } 54\end{array}$ & $\begin{array}{l}\text { Right upper lobe. } \\
\text { Left lower lobe. }\end{array}$ & $\begin{array}{l}\text { Simple. } \\
\text { Simple. }\end{array}$ & Lobectomy. & $\begin{array}{l}\text { Still under } \\
\text { treatment } \\
\text { but well. }\end{array}$ & - \\
\hline
\end{tabular}

liver. Bile may be found in the sputum in such cases. Liver hydatids, and particularly those near the upper surface of the viscus, commonly become infected and rupture through the diaphragm, discharging their contents either into the lung, the pleural cavity, the mediastinum, or the pericardium. If daughter cysts grow in the lung, and no liver hydatid is. present, the cause is generally that a simple cyst has undergone partial rupture.

In the present series daughter cysts were coughed up by 3 patients from primary cysts in the lung, and hydatid elements-but no membranes-were found in the sputum of one of the others. The first patient (E. S. S.) we saw had been operated upon in 1935 by Mr. Stout, of Wellington, New Zealand, who removed intact a simple univesicular cyst from the right upper lobe. The chest was closed without drainage. Convalescence was stormy at first; on the third postoperative day she developed a painful paroxysmal cough with surgical emphysema and 
began to expectorate dark, bloodstained sputum. On the tenth day she had an haemoptysis and staining persisted for several weeks. She was discharged to her home six weeks later, and although she was convalescent she had no energy and could not return to nursing for six months. After three months the cough reappeared, it was paroxysmal, irritating, and productive of mucus, and then she began to cough up large numbers of tiny cysts ; they were hard like pearl beads and " they popped like seaweed when squeezed." The largest was about the size of a bean, and, in addition to whole cysts, fragments of membrane were also expectorated. This continued at intervals during the ensuing year; a sneeze or a hearty laugh might produce two or three cysts, and a cough would cause them to appear unexpectedly in the mouth. In 1940 she was nursing in England, and by that time had a radiographic opacity in the right upper lobe and a cystic swelling in the chest wall deep to the right breast. She was operated upon by Brock, who found a cavity containing two daughter cysts and a number of smaller hydatid elements. These were removed without difficulty, but four years later a secondary cyst grew in the vicinity of the scar in the chest wall ; this was also removed, and so far there has been no recurrence.

Five other patients had daughter cysts 'or secondary echinococcosis in the lungs or the pleural cavity, but none of them coughed up hydatid elements.

The first (W.D.R.) was a man with bilateral simple cysts. The parasite on the right was successfully removed, and whilst he was waiting for the second to be operated upon it partially ruptured. He coughed up the fluid but not the membranes, and in the process nearly died from the effects of anaphylaxisnamely, severe bronchospasm, dyspnoea, tachycardia, and cough. Less than a year later three daughter cysts had grown within the original adventitia in the left upper lobe and were treated by lobectomy. This patient is now well.

The second was a woman (M. A. J.) suffering from two cysts in the right lung as well as others in the liver and the spleen. The two last were calcified. Both the lung cysts were operated upon by removal and drainage; both had areas of calcification in their walls at operation; both were infected with foul-smelling pus containing mixed organisms including $B$. coli, and both contained hundreds of tiny daughter cysts intact and flourishing in the pus. After operation daughter cysts were discharged from the drainage tube for some months. A year later she was convalescent and, although no communication with the liver was ever found and no bile was discharged, this is probably a case in which a liver hydatid had burst through the diaphragm and caused secondary disease in the thorax.

The third (E. G.) was a woman who had had "heart attacks" for five years. She had a large opacity at the left base, and at operation two simple cysts were found, one very large, the other small. They were contained within a dumb-bellshaped cavity, the inner and smaller component of which lay in the lung and the larger in the pleural cavity. The whole lesion was sealed off by dense adhesions, 

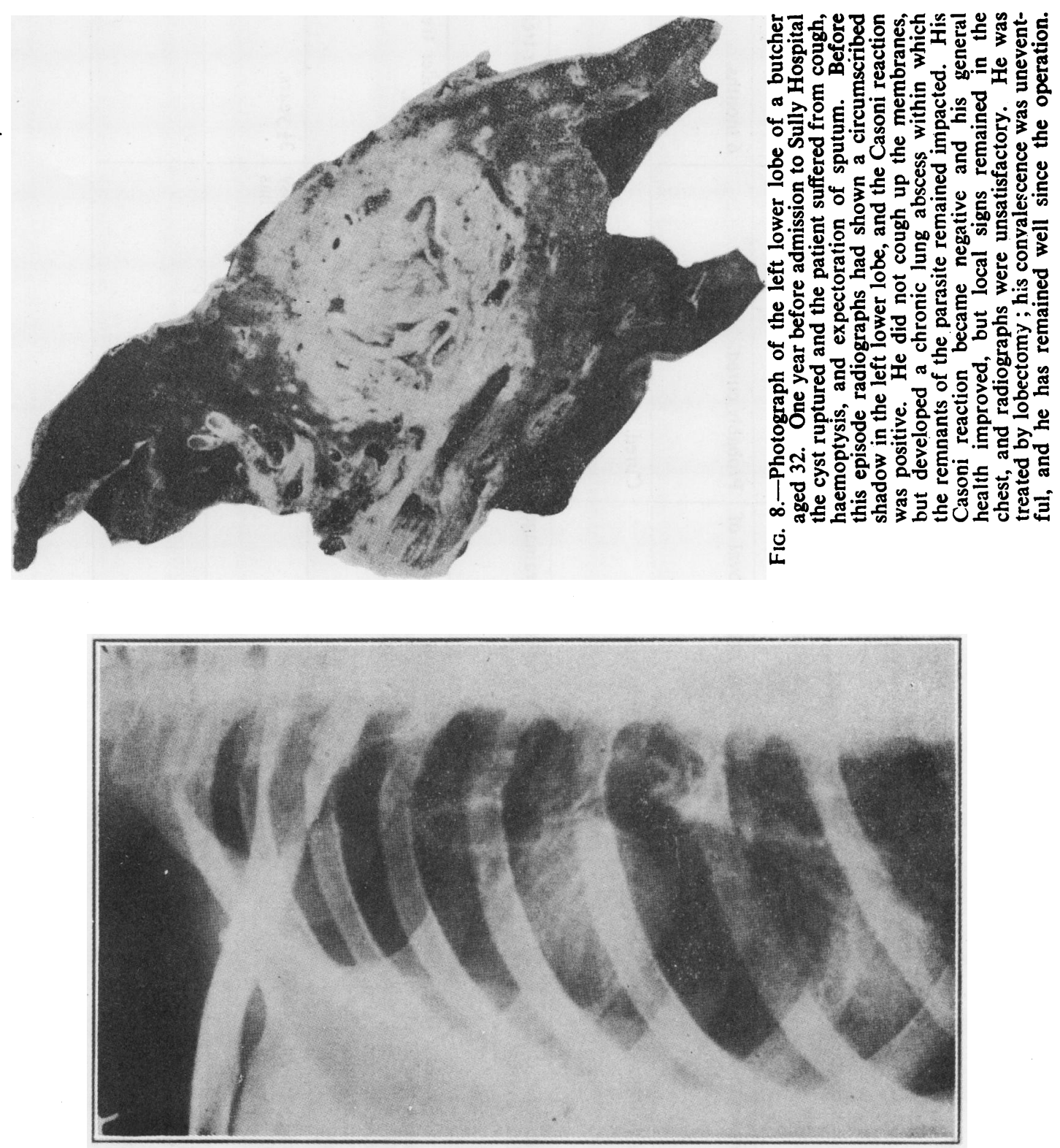

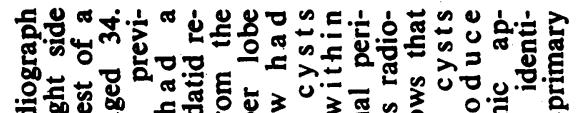

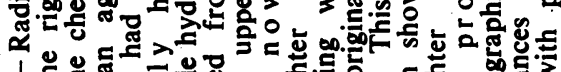

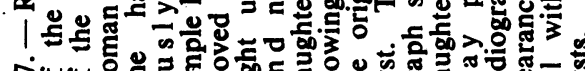

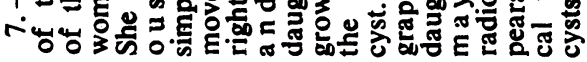
ن 


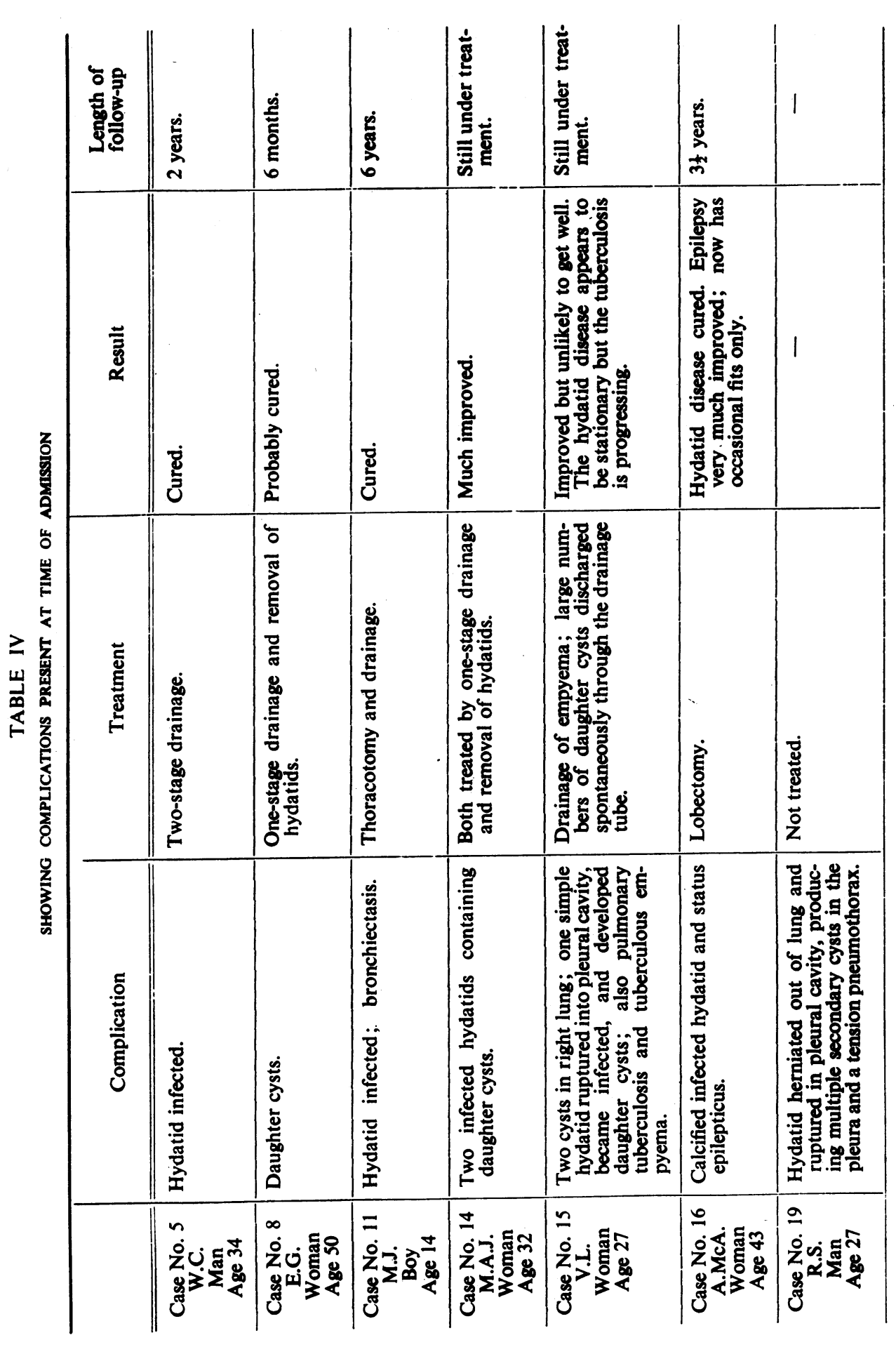

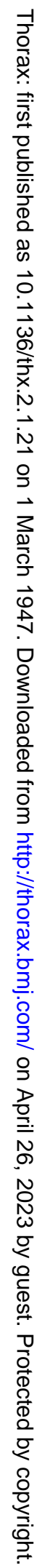




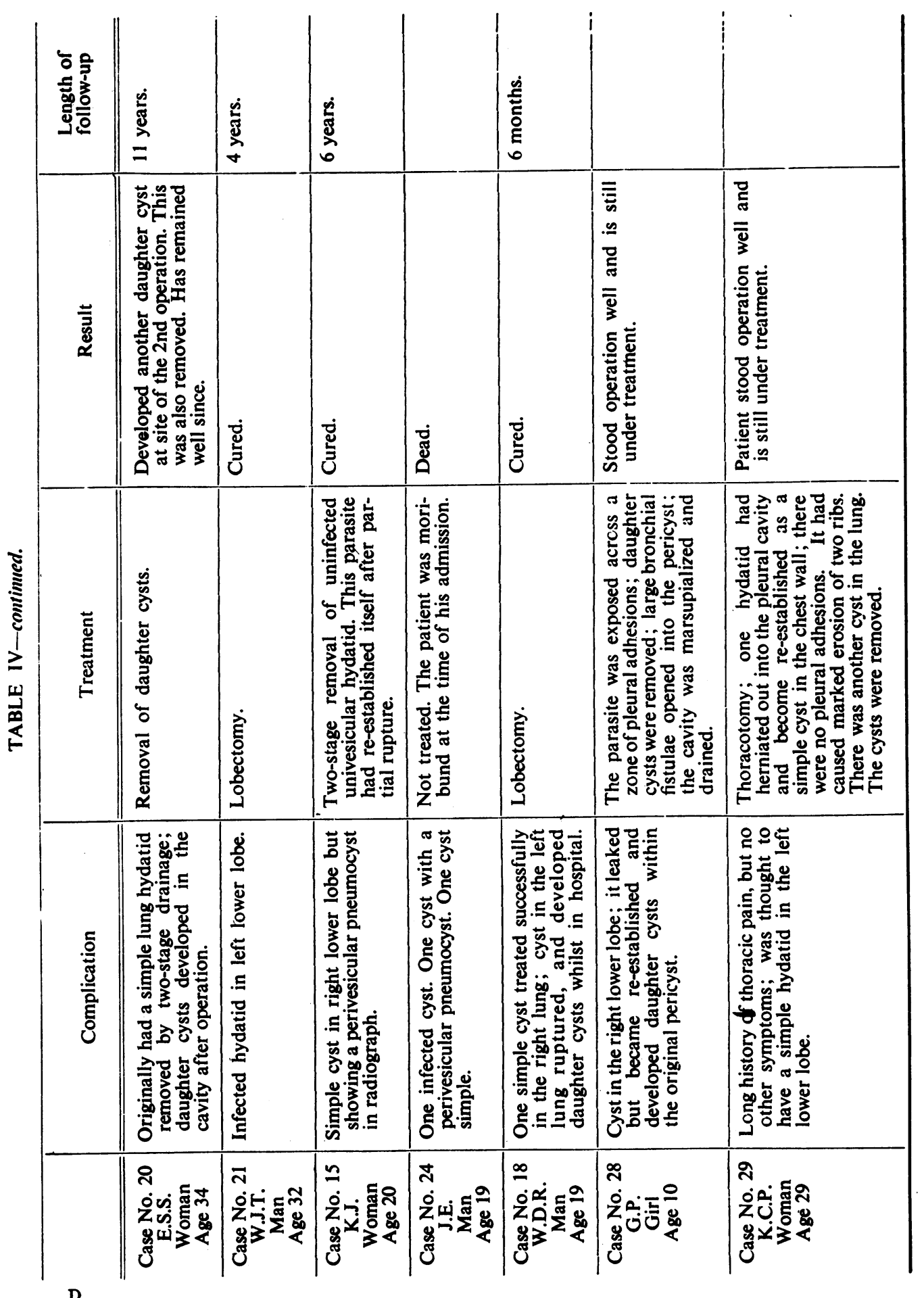

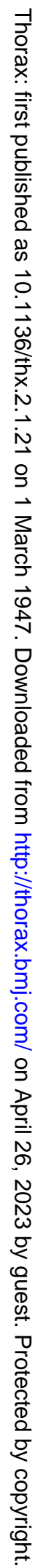


and the parasites were removed without difficulty. Convalescence has been slow, but the residual cavity is closing.

The fourth (R.S.) was a man suffering from a tension pneumothorax. His original cyst had herniated out of the right upper lobe, fallen to the bottom of the pleural cavity, ruptured, and seeded the whole space with hundreds of secondary cysts. He was not treated.

The fifth (G. P.) was a girl aged 10 who had lived all her life on a sheep farm. Six months before admission she began to cough up blood in small amounts, and apart from this there were no other symptoms. Serial radiographs showed a cyst in the right lower lobe which had partially ruptured and in which a fluid level appeared. In a short time this level disappeared, and at operation it was found that daughter cysts had formed within the original pericyst. There was pus between these daughter cysts and the pericyst, and two large bronchial fistulae opened into the cavity.

These cases show that daughter cysts may develop in the lung after the original parasite has been removed. They grow from hydatid elements left behind at the operation or from scolices in liquid which has been spilt. They can form when a cyst which has ruptured is not totally expelled through the bronchial tree. Anaphylactic reactions are common in this type of incident. When a cyst ruptures the communication between the laminated membrane and the bronchus is generally of a valvular type ("en bec de flute") at first, so that the fluid contents are extruded slowly and infection does not occur; in these circumstances the parasite may re-establish itself or form daughter cysts. There are all degrees between this and the patient who voids the whole parasite and its contents in one sudden paroxysm of cough. If a fistula between the cyst and an adjacent bronchus persists and infection enters the cavity, the debris from the decomposing hydatid acts in the same way as the slough in a putrid lung abscess and tends to perpetuate the lesion.

Daughter cysts can live in pus and continue to multiply after a cavity has been drained ; in the abdomen it is not unusual to find daughter cysts alive in bile or infected urine. They are generally small and numerous and can live in a cavity whose walls are not only inflamed but partially calcified. Calcification does not necessarily signify death of the parasite. Daughter cysts are not always a sequel to rupture of a liver cyst into the lung, and even if this happens hydatid elements may never be found in the sputum. A liver cyst which has ruptured into the lung does not necessarily produce a bile containing discharge from the operation wound or in the sputum.

Table IV gives brief details of the complications (including daughter cyst formation) which were present when the patients first came to us for treatment. These cases give an indication of the problems which arise as soon as complications befall the parasite, and in themselves are an argument for operating upon 

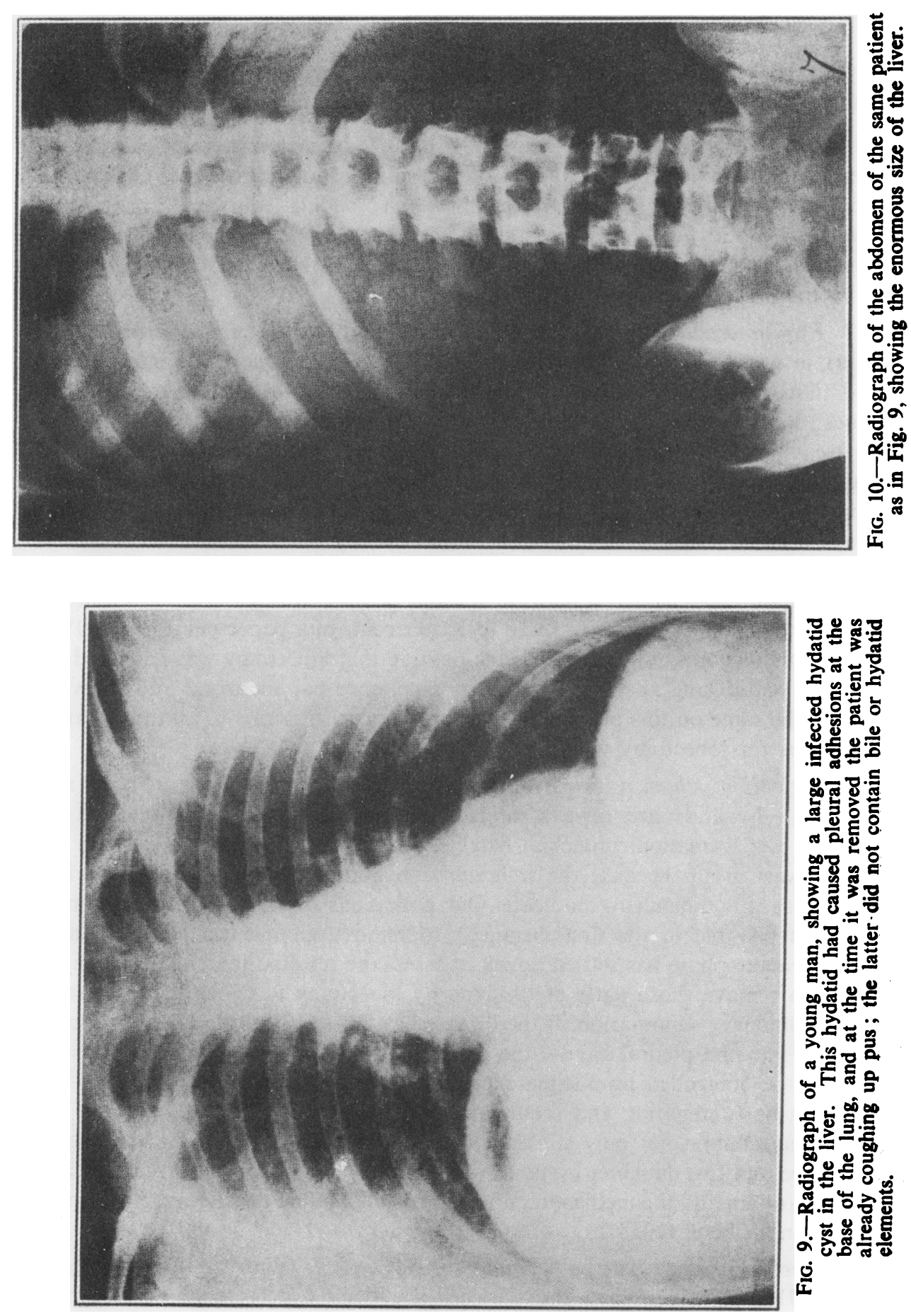
simple cysts as soon as possible. The following are the complications which may require treatment:

1. Daughter cyst formation (Fig. 7).-In our experience it is not easy to tell when daughter cysts are forming, but the possibility should always be entertained in patients who are supposed to have achieved a "spontaneous cure" or in those in whom hydatid fluid has been spilt at the time of operation. The lesion produced can be treated in the same way as a simple cyst, but lobectomy is generally the method of choice.

2. Ruptured and infected cysts (Fig. 8).-The problem is similar to that which occurs in foetid lung abscess. In both lesions the abscess contains infected and dead tissue, which in hydatid disease is composed of the disintegrating membranes ; in both of them the decision before the surgeon rests between conservative treatment or open drainage in the early cases, and lobectomy in those of long standing. My own preference is to do a lobectomy in hydatid disease because, when I have performed this operation, the lesion found in the resected part has always been so extensive as to be incurable by any other means ; because it is particularly in this group that permanent sinuses and a "lattice lung" develop if external drainage has been performed ; and because Dew (1928) states that the mortality of drainage ranges from 20 to 30 per cent. In a paper published in 1944 with Dillwyn Thomas, we expressed the opinion that lobectomy was indicated for chronic hydatid lung abscess ; since then experience has increased and my view remains the same on this point, although I no longer subscribe to all the tentative indications for lobectomy which we suggested at that time.

3. Patients in whom a liver hydatid has ruptured into the thorax (Figs. 9 and 10).- Such hydatids are always infected and are commonly complicated by daughter cyst formation, bronchial fistulae, and calcification. They comprise the most serious group because the inflammation and hydatid disease is so widespread that it is difficult to eradicate. Our policy has been to drain the lesion as widely as possible in the first instance; to remove all hydatid elements, and, when the acute phase has settled down, to assess the residual pulmonary damage ; finally, to remove those parts of the lung by lobectomy in which there is established pulmonary suppuration. If the disease has not involved the lung but simply extended into the pleural cavity, the empyema and subphrenic suppuration can generally be controlled by adequate pleural drainage, but inflammations of this type may be fulminating and require wide: open drainage to effect a cure. The pleura may contain not only stinking pus but disintegrating sheets of laminated membrane and live daughter cysts. Dew describes cases in which perforation into the pericardium and the mediastinum had occurred, and he discusses the treatment of these in his book (1928).

4. The persistent cavity or " empty sac" (Lendon) (Figs. 11, 12, 13, 14, 15, $16,17,18,19,20)$.-When the parasite has been expectorated or surgically 

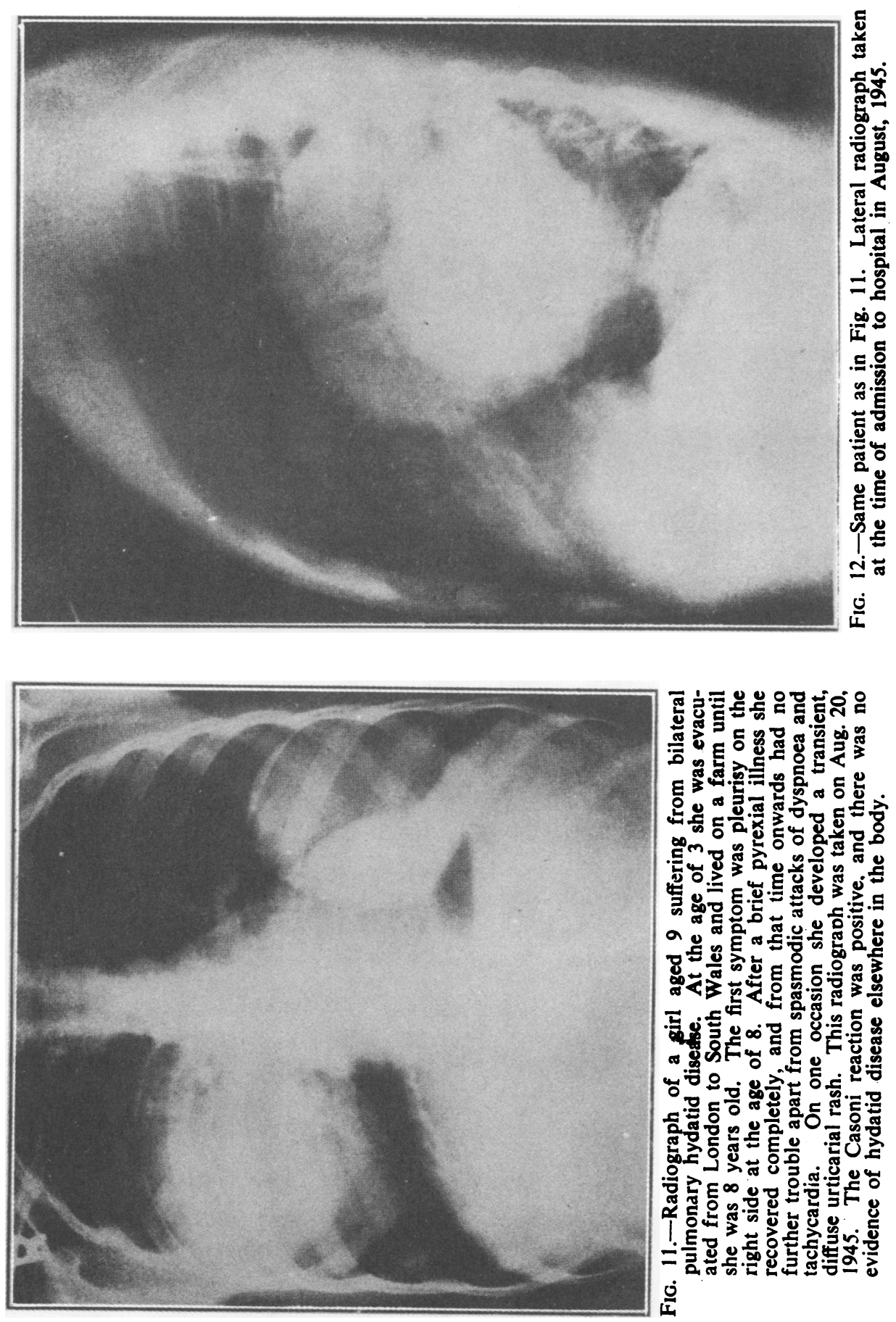


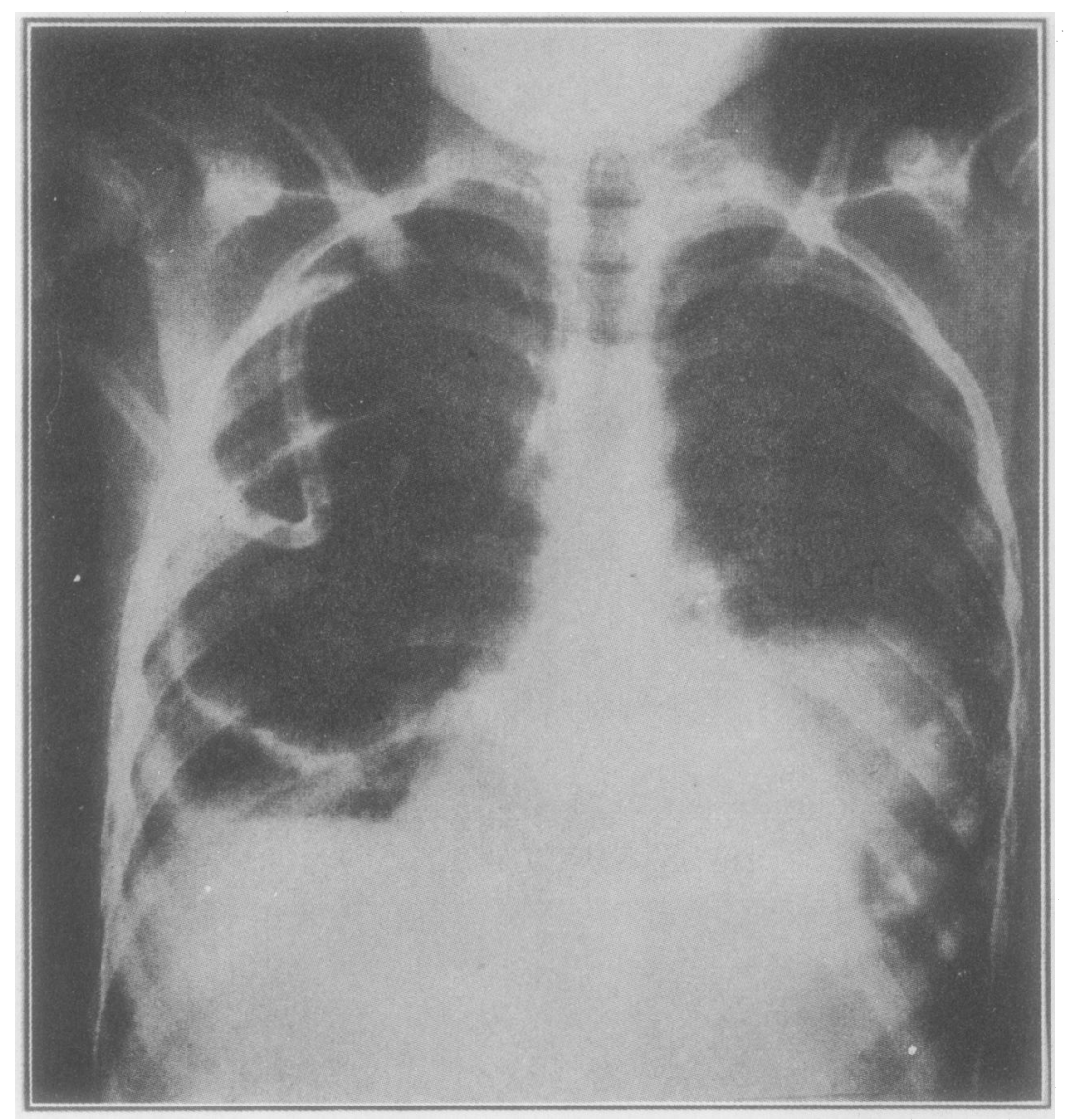

Fig. 13.- Same patient as in Fig. 11. Radiograph taken on the day after the cyst in the right lung had been removed by open thoracotomy. No adhesions were found in the pleural cavity, and the parasite was removed without difficulty. Note the apical pleural suction catheter, and the "empty sac" in the right lung.

removed, a space, or cavity, is left in the lung. Fortunately this "sac" generally obliterates quickly and does not collect liquid within it or become infected. But the cavity does not always disappear in this way, and if it persists for as long as six months it is likely to be a permanent legacy and to become lined by epithelium from the communicating bronchi. The patient then has a lung cyst, and although this may remain uninfected for years and may never cause symptoms, both haemorrhage and infection are ever-present dangers. The type of case in which a persistent cavity remains after removal of the parasite is that in which the adventitia is found to be thick and tough at the time of operation so that it hinders the expansion of the surrounding lung which should obliterate the space. Another unfavourable type is that in which inflammation 

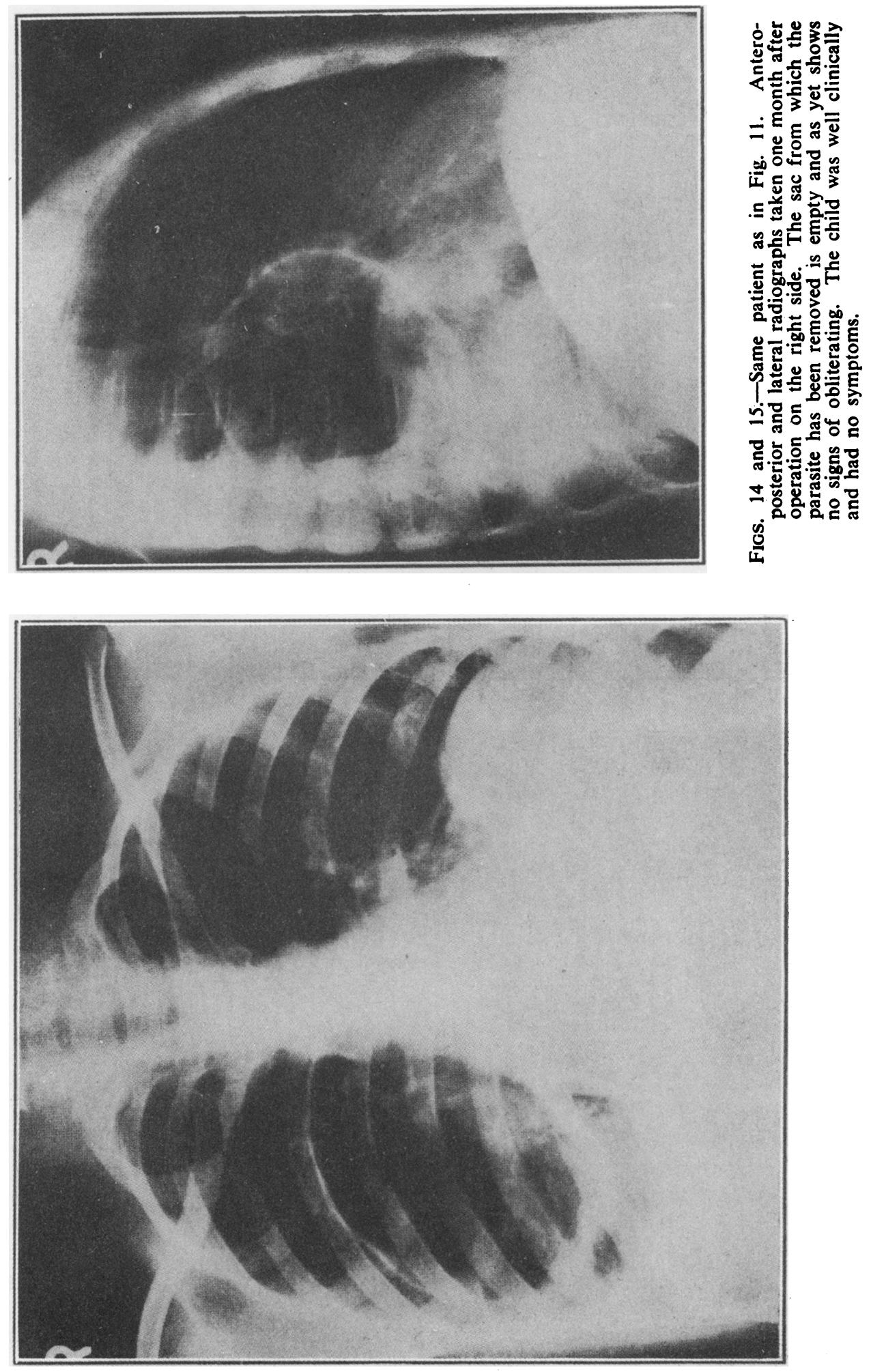


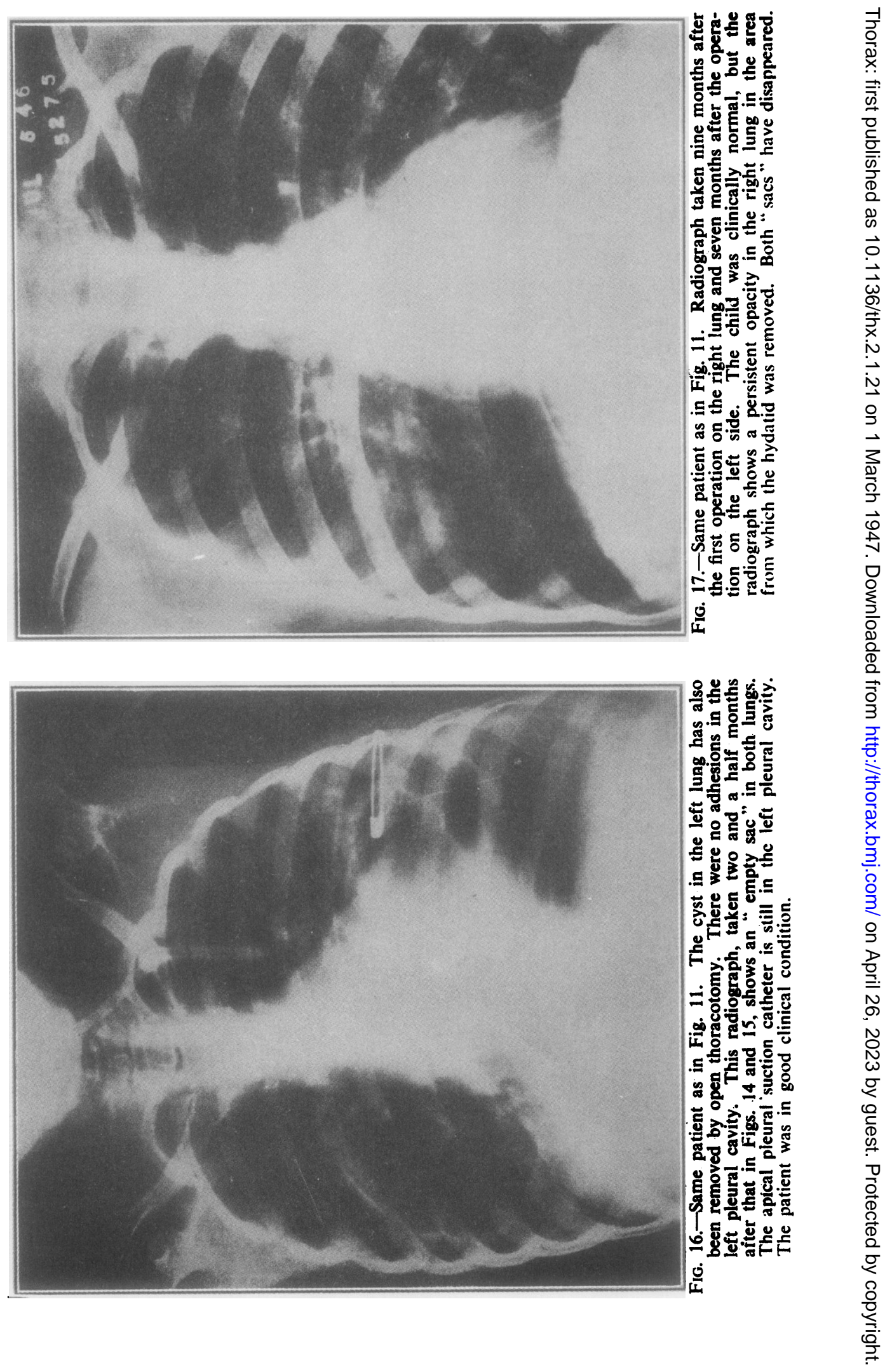



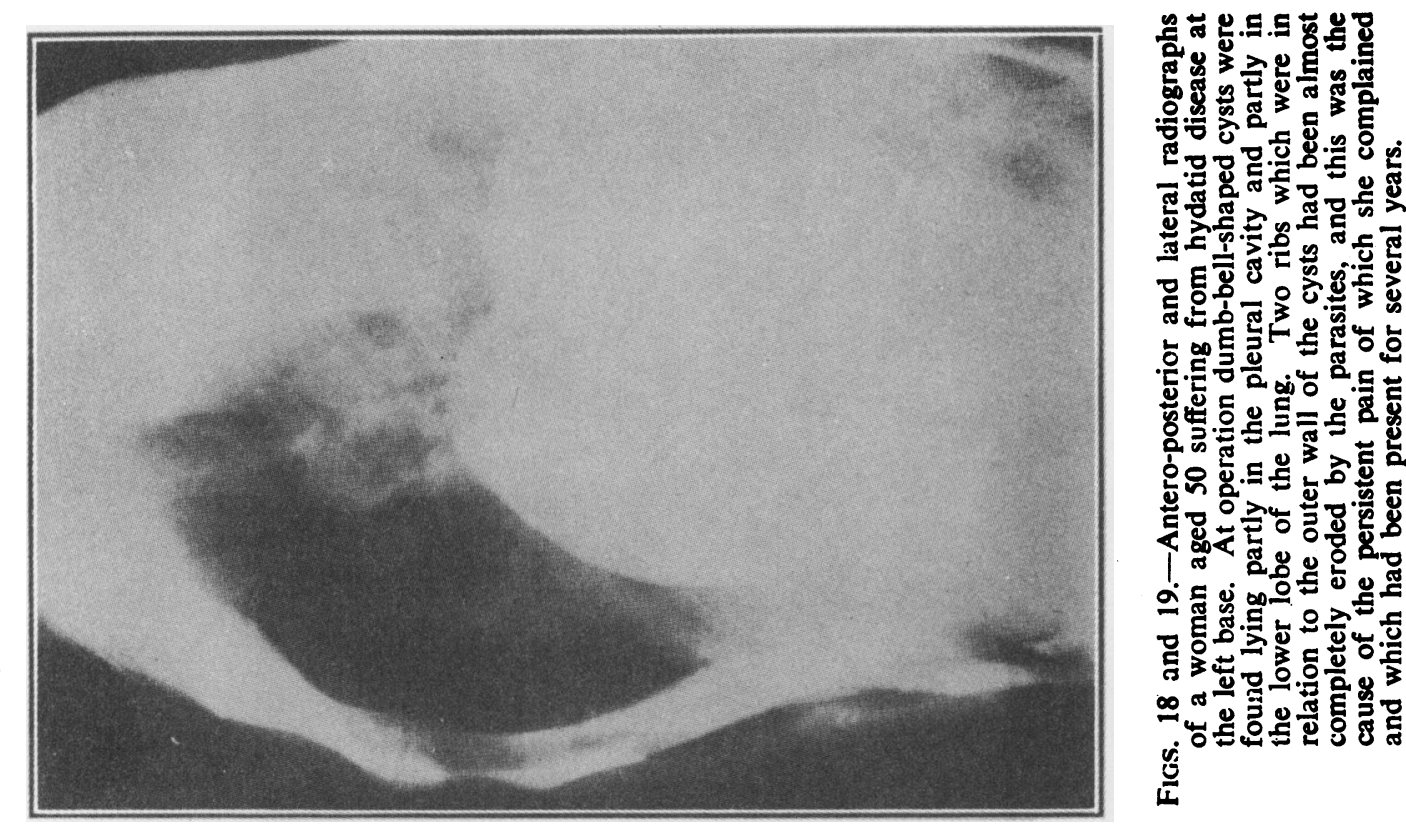


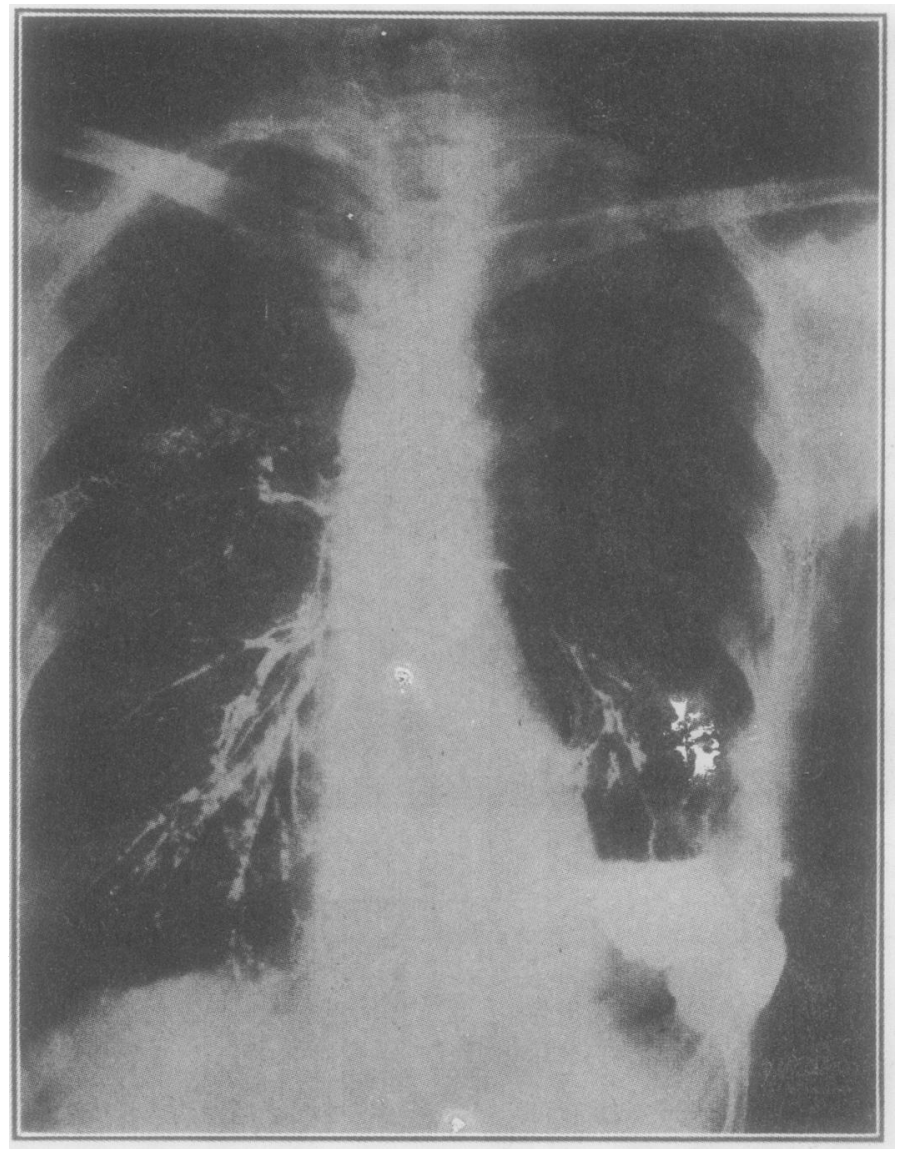

Fig. 20.-The same patient as shown in Figs. 18 and 19, but several months after operation. The area which was originally occupied by the hydatid cyst is now clear, but a bronchogram shows the oil running into a large persistent cavity (empty sac) which communicates freely with several bronchi at the base of the lower lobe. This patient will probably need a lobectomy to cure this lesion.

has cccurred around a simple hydatid and led to pulmonary suppuration or bronchiectasis, and a third is the case in which daughter cysts have formed. As daughter cysts only grow when the life of the parasite has been threatened by partial or complete rupture, it follows that the adventitia is dense in these cases and inflammations are often present around the cysts. I believe that as soon as there is evidence that a cavity is likely to persist in the lung lobectomy is the treatment of choice. It may be argued that expectant treatment is reasonable if the patient who has an "empty sac" is symptomless, but sooner or later complications are likely to develop in that empty sac, and these should be anticipated. 

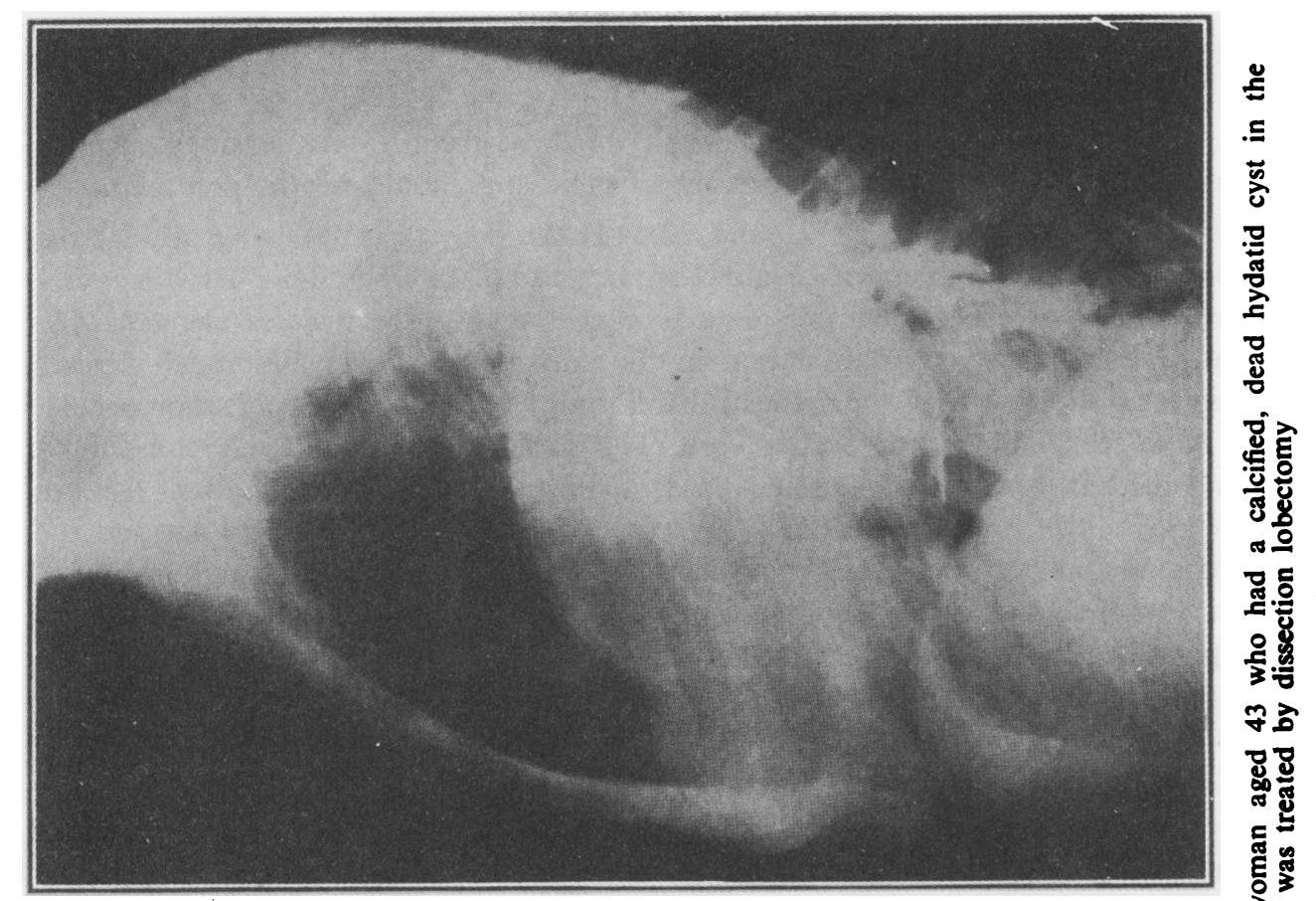

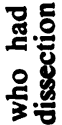

学

马ु

हू

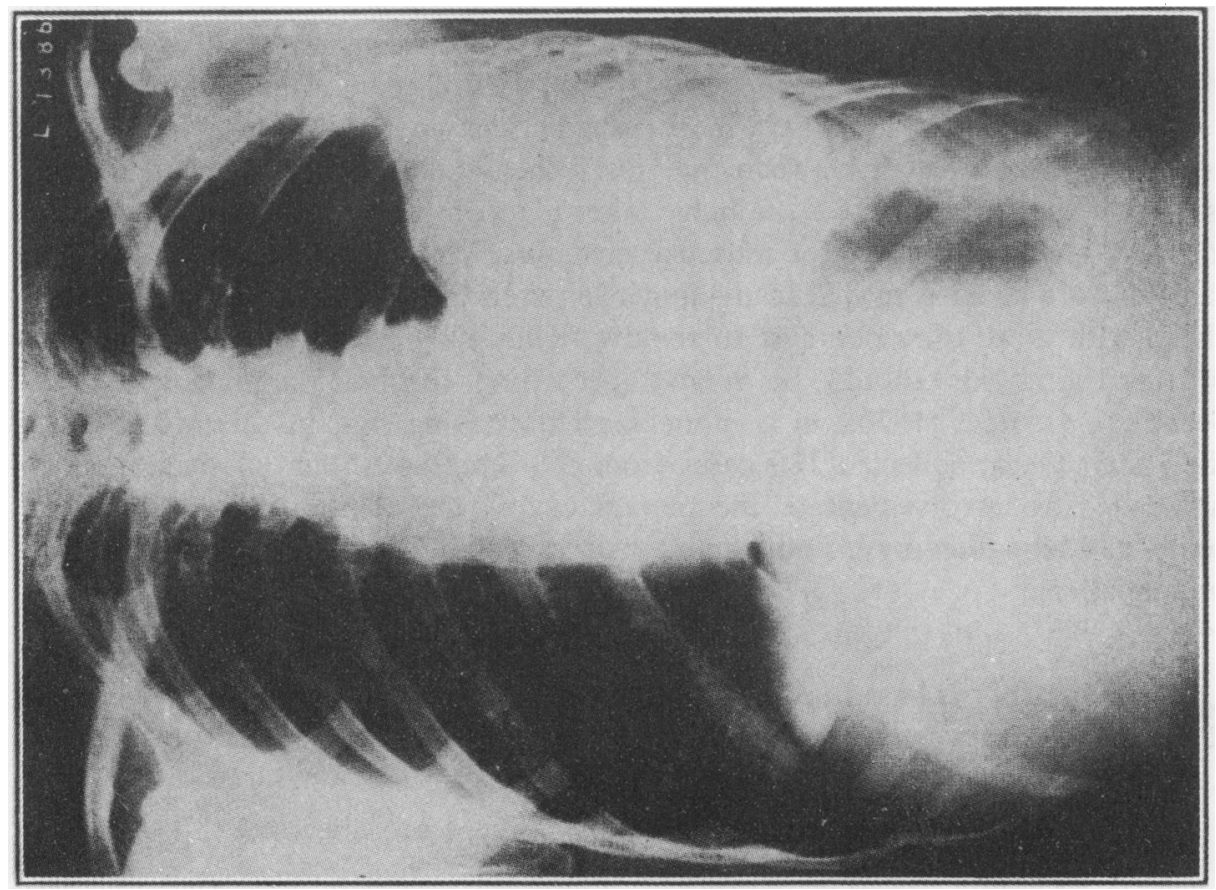


Operations such as thoracoplasty, phrenic avulsion, and measures such as artificial pneumothorax are wrong in principle and should not be practised.

5. The dead cyst (Figs. 21 and 22).-Hydatid cysts in the lung seldom die except as a result of rupture or infection, but a parasite in the lung can die at any time and, if it does, it behaves as a foreign body. As the hydatid elements disintegrate they cause inflammation in the surrounding parts and much fibrous tissue grows to wall off the area. In this fibrous capsule dense calcification occurs. I have seen and treated such a case. The patient was submitted to lobectomy and the left lower lobe was removed. It contained a dead hydatid, about the size of an orange ; there was a thick layer of calcification in the adventitia and the remainder of the lobe was replaced by fatty tissue, acute and chronic suppuration, bronchiectasis, and lymphadenitis. At the time it was decided to do the operation the patient had no pulmonary symptoms, but it is certain that if this lobe had been left, or the hydatid treated by drainage, the end result would have been unsatisfactory. Dead hydatid cysts should be regarded as dangerous foreign bodies in the lung.

In this group of cases the difficulties of achieving a cure by surgical means are obvious, but, as the patient has no other hope of avoiding invalidism, drastic measures must often be tried. Not the least of the difficulties which confront the surgeon is that of assessing the anatomical extent of the lesions before operation, and I shall quote two examples of the pitfalls which occur. In a paper concerning "subserous cysts" (i.e., mediastinal cysts) Bird makes these observations. "Subserous cysts are rare. They are usually seen in the vertebral region and posteriorly may present between the ribs. When such a thing occurs a mistake is born at the same time, for the bulge takes place in the vicinity of the rhomboid muscles, a common place for muscular hydatids. The surgeon thinks it a simple case, but his incision may lead his finger between the ribs into the depths of the chest, with more than one cyst to remove. Thus bulgings in the neighbourhood of the rhomboids should be treated according to their large possibilities." Secondly, Georgel (1930), in a monograph describing hydatid disease affecting the spinal theca, collected 180 cases from the literature. Some of these patients had extensive involvement of the pleural cavity, the chest wall, and the lung, some had daughter cysts, and some had ruptured through the lung into the bronchial tree.

\section{SUMMARY}

1. This paper is based upon 30 patients who suffered from pulmonary hydatid disease and who were seen and treated in England and Wales between 1935 and 1946. These patients harboured 38 hydatid cysts in their lungs.

2. The pros and cons of conservative treatment are analysed.

3. A technique for the removal of simple univesicular cysts from any part of the lung is described, and the arguments for and against every step in the 
operation are discussed. No set treatment can be applied to every case, and no surgical treatment is free from risk.

4. A series of complicated cases are described, and the indications for lobectomy in these circumstances are discussed.

\section{APPENDIX}

In this series of 30 patients the iollowing additional facts are of interest:

(a) Age incidence at the time of admission for treatment:

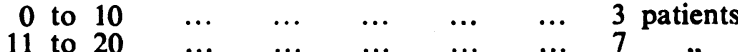

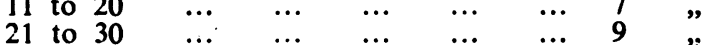

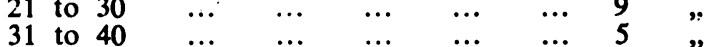

$$
\begin{aligned}
& 41 \text { to } 50 \text { 일 } \\
& 51 \text { to } 60 \\
& \text { Men } \\
& \begin{array}{llll}
\cdots & \cdots & \cdots & 4 \\
\cdots & \cdots & \cdots & 2 \\
\text { Boys } & & \multicolumn{2}{c}{\text { Girls }}
\end{array}
\end{aligned}
$$

Barnett, L. E. (1914). New. Zeal. med. J., 13, 145.

Barnett, L. E. (1938). Austral. New Zeal. J. Surg., 8, 104.

Barrett, N. R., and Thomas, D. (1944). Brit. J. Tuberc., 38, 39.

Bellard, L. (1924). Thèse Paris.

Bird, F. D. (1925). Med. J. Austral., 2, 505.

Bond, C. J. (1891). Brit. med. J., 1, 795.

Brock, R. C. (1942). Guy's Hosp. Rep., 91, 99.

Ceballos, A. (1943). J. thorac. Surg., 12, 553.

Christie,' H. K. (1938). A ustral. New Zeal. J. Surg., 8, 373.

Davidson, L. R. (1944). J. thorac. Surg., 13, 471.

Dévé, F. (1922). La Normandie Medicale, 32, 161, 189.

Dew, H. R. (1928). Hydatid Disease. Sydney. The Australasian Medical Publishing Co.

Edwards, F. R. (1946). Personal communication.

Finochietto, R. (1924). Siglo. med., 78, 158.

Finochietto, E. (1927). Practitioner, 119, 10

Fossati, A. (1911). Rev. méd. Uruguay, 14, 97.

Georgel, H. (1930). L'Echinococcose Rachidienne. Paris. Librairie Arnette.

Howells, N. (1938). Ann. Rep. Chief Med. Off. Health of M.O.H., 192. London.

Lamas, A. (1916). Rev. méd. Uruguay, 19, 765.

Lendon, A. A. (1902). Hydatid Disease of the Lung. London.

Lepicard, S. (1912). Thèse Paris.

Peacock, T. B., and Hicks, J. W. (1863). Trans. Path. Soc. Lond., 15, 247.

Phillips, E. W. (1930). Arch. Surg., 21, 1324.

Thornton, J. K. (1883). Med. Times and Gaz., 1, 89.

West, S. (1909). Diseases of the Organs of Respiration, 2nd Edit. London. 